\title{
Why the integration of demographic and site-based studies of disturbance is essential for the conservation of jarrah forest fauna
}

\author{
Grant Wardell-Johnson', Michael Calver², Denis Saunders ${ }^{3}$, Simon \\ Conroy ${ }^{4}$, Barbara Jones ${ }^{2}$
}

'Natural and Rural Systems Management, University Of Queensland, Gatton, 4343

${ }^{2}$ Biological Sciences, Murdoch University, Murdoch, Western Australia 6150

${ }^{3} \mathrm{C} /$ - CSIRO Sustainable Ecosystems, GPO Box 284, Canberra ACT 260 I.

${ }^{4}$ Department of Zoology, The University of Western Australia, WA 6907, Nedlands, Australia.

Correspondence to G Wardell-Johnson, Fax +6I 75460 I324, E-mail g.wardelljohnson@uq.edu.au

\begin{abstract}
We review recent studies of the impacts of disturbance on the fauna of the jarrah forest, southwestern Australia. In particular, we examine five case studies that provide alternative approaches to researching disturbance impacts. Assessing site-based studies of patterns of fire regimes lead us to argue that point measures of frequency are inadequate to understand scale and pattern across landscapes. Rather, extrapolating from site-based data to draw conclusions on landscape-scale changes may obscure fine-scale heterogeneity in disturbance, which is critical to the conservation of biodiversity. We review species-based studies and conclude that assessments of demographic trends are more effective than surveys in determining impacts, and providing early warning of declines because they highlight threatening processes. Furthermore, risk analysis, when critical aspects of the biology of participating species are weakly known, may lead to misclassification of species and poor decisions on conservation priorities. The review of recent impact studies of logging on jarrah forest fauna demonstrates that logging interacts with predation by foxes to threaten arboreal mammals. Hence, measures to protect threatened vertebrates benefit many species. However, while concentrating on proximate causes of fauna decline produces immediate conservation gains, long-term conservation requires an understanding of both proximate and ultimate causes and their interaction. We urge the acquisition of reliable, site-based demographic data that allows predictive modelling for species, and hence testing of alternative hypotheses regarding impact, distribution and decline. We also seek the integration of data and approaches to enable landscape-scale patterns to be discerned and interpreted for effective conservation planning.
\end{abstract}

Key words: integration, frogs, recruitment, demography, metamorphosis, mark-recapture models, survival, fire, disturbance, regime, intensity, frequency, experimental design, population viability analysis, hardwood forests, jarrah, endemism, landscape, logging, impacts, risk analysis, predation, marsupials, hollow-using fauna.

\section{Introduction}

The forested ecosystems of south-western Australia occur over an area of about 4.25 million hectares in three biogeographic regions; Swan Coastal Plain, Jarrah Forest and Warren (IBRA bioregions sensu Thackway and Cresswell 1994). In each of these bioregions, forests occur in a matrix of vegetation types reflecting an extraordinarily long and complex geological and climatic history. The importance of these ecosystems for conservation is demonstrated by their remoteness from forested regions in eastern Australia, by the small proportion of the State that is forested $(<1 \%)$, and by the extraordinary diversity of south-western Australia in comparison with forested regions at similar latitudes elsewhere in the world (e.g., Wardell-Johnson and Horwitz 1996, Gioia and Piggott 2000). The forested ecosystems of south-western Australia are important for many endemic species that are relicts from previously wetter climatic periods and for species reduced to refugial status by extensive clearing of neighbouring bioregions, such as the Avon and Eyre (Hopper et al. 1992, McKenzie et al. 1996, Hopper and Wardell-Johnson in press). They also include levels of species diversity that belie the seemingly homogenous appearance of the landscapes of the region. Our understanding of their unique biota continues to grow (e.g., Wardell-Johnson and Roberts 1993, Roberts et al. 1997, Gioia and Piggott 2000, Hopper and WardellJohnson in press).

Given this extraordinary diversity, the proximity of major population centres of the State such as Perth, and the availability of substantial, readily exploited resources such as hardwood timber, bauxite, coal and mineral sands, it is not surprising that considerable public interest in the variety of potential forest uses has led to major political (e.g., State election of 2000) and scientific (e.g. Abbott and Christensen 1994, 1996, Abbott and Burrows 1999, Wardell-Johnson and Horwitz 1996, 2000, Calver et 
al. 1996, 1998) conflict since prior to the introduction of the Forests Act in 1918, but particularly in recent years. Substantial tracts of forest have been cleared for agriculture (Jarvis 1981), while the remainder is the basis of a range of industries including mining, logging, tourism, wildflower picking and honey production, as well as supplying a range of services including water catchment protection and nature conservation (Dell et al. 1989, Christensen 1992). Prescribed fire is used widely in the forests to reduce fuel loads, lower the risk of more intense wildfires and for habitat management for particular species and communities (Christensen and Abbott 1989).

Studies of the impacts of disturbances on the ability of the south-west forest ecosystems to provide ecosystem services in the face of wide-ranging use were sparse until the late twentieth century, and the few studies available were restricted in their methodological approaches (RAC 1993, Calver et al. 1998). Reviews of the impacts of environmental disturbances were provided in the early 1990s by Wardell-Johnson and Nichols (1991) for the south-west forests, and Wardell-Johnson and Christensen (1992) for the forested ecosystems in which karri Eucalyptus diversicolor forms a component. Christensen (1997a) reviewed the impacts of environmental disturbances on fauna in the south-west of Western Australia for the Western Australian Regional Forest Agreement, taking an optimistic view of the long-term conservation status of the fauna if environmental disturbances are managed carefully. Control of the introduced Red Fox Vulpes vulpes was emphasised and he highlighted research priorities in the areas of conservation of hollow-using fauna and animals near the end of food chains.

The most recent review (Calver and Dell 1998) concentrated on environmental impacts on the 16 mammal species and 22 bird species from the south-west forests which had at some time been listed as endangered. Foxes were implicated in the current conservation status of $62 \%$ of the mammal species, while $44 \%$ of them were negatively impacted by feral cats Felis catus, $44 \%$ by agricultural clearing and $44 \%$ by changed fire regimes. For the bird species recognised, changed fire regimes had the greatest negative impact (45\% affected), agricultural clearing affected $41 \%$, draining of wetlands affected $32 \%$ and grazing by livestock affected $22 \%$. Logging operations were implicated in the conservation status of only one mammal and no bird species. However, in our opinion, confident assessment of the causes of conservation status was hampered by poor base-line data, few impact studies and a preponderance of circumstantial or anecdotal, rather than experimental, evidence.

The limitations reported in these reviews promoted divergent opinions on the extent and severity of impacts. Some authors considered that the database was adequate and that impacts were minimal (Abbott and Christensen 1994, 1996, Armstrong and Abbott 1995, Christensen 1997b). Others recognised that information was lacking but formed the conclusion that serious impacts were unlikely (Nichols and Muir 1989), argued that the question remained open for lack of detailed studies of impacts (Calver and Dell 1998), or that deleterious impacts were already occurring (Mawson and Long 1994, 1997).
The divergence of opinion stimulated an extensive range of studies of environmental impacts in the south-west forests over the last decade (see summary in Burrows et al. 2001, p. 15), many of which were published after the reviews by Christensen (1997a) and Calver and Dell (1998). These studies addressed not only impacts such as logging, fire and bauxite mining, but also critical methodological questions about how best to evaluate impacts in forested environments. The research employed a range of experimental designs, fauna surveys, observation studies, population viability analyses and risk analyses, each of which has strengths and limitations. Pressing questions relating to fauna were examined, including the following that we regard as priorities.

At what scale should management actions be implemented to conserve biodiversity and what are the proximate and ultimate causes of fauna decline in the south-west? To what extent are disturbances interactive? Population and autecological questions included; how can risk to fauna be assessed to guide conservation management priorities and what variables should best be assessed or monitored to establish impacts or provide early warning of declines? There also remains the question as to whether logging threatens the long-term conservation status of forest fauna. It is timely to review the results of contemporary studies to consider the relative value of different approaches to resolving critical questions about impacts as well as the findings and their management implications. We therefore include five case studies to determine how well these current approaches contribute to ecological understanding for conservation management planning.

\section{Landscape-scale patterns and disturbances}

The three biogeographic regions including the southwestern forested ecosystems are marked by an ancient geological history encompassing prolonged leaching and erosion, with deposition and lateritization of the land surface (Wardell-Johnson and Horwitz 1996). This results in characteristically poor soils in a topographically flat landscape of complex form (Churchward et al. 1988, Tille and Lantzke 1990). The most striking features of the three forested bioregions of south-western Australia are their lack of topographic relief and their apparent homogeneity as exemplified by the dominance of three regionally distributed eucalypts; jarrah Eucalyptus marginata, marri Corymbia calophylla and karri (Wardell-Johnson and Horwitz 1996, Wardell-Johnson et al. 1997). Jarrah and marri occur throughout the three bioregions, with the latter predominating on more fertile sites. Karri dominates areas of tall open-forest on loamy soils of the Warren Bioregion and occurs in the least floristically diverse forested community of the region. The Darling Scarp is the dominant topographic feature (300 - $400 \mathrm{~m} \mathrm{ASL)}$ of this bioregion on the western margin of the Archean Yilgarn Block, which has itself, formed the nucleus of the present Australian continent (Johnstone et al. 1973).

The subdued landscapes of south-western Australia occur as a mosaic of local ecosystems and landforms that repeat in a similar form over areas that are kilometres wide but 
typically vary topographically by tens rather than hundreds of metres. Several attributes, including geology, soil types, species assemblages, climate and natural disturbance regimes tend to be repeated across the area (WardellJohnson and Horwitz 1996). Considerable complexity in environmental and floristic pattern has been documented in the forested ecosystems of south-western Australia (e.g. Gibson et al. 1994, Wardell-Johnson and Williams 1996, Wardell-Johnson et al. 1997, Mattiske and Havel 1998, Havel 2000). Figure 1 shows variation in patterns of vegetation structure associated with outcropping, swamp and open forest near Denmark in the southern part of the Jarrah Forest Bioregion. Mattiske and Havel (1998) and Havel and Mattiske (2000) recognised the link between floristic complexes and climate and geomorphology in the forested south-west and provided a series of maps of 315 vegetation complexes in 12 geologically discrete environments in the major part of this area. These maps were based partly on the landform soils units of several authors including Churchward et al. (1988), and Tille and Lantzke (1990). Christensen et al. (2001) provided broad vertebrate fauna habitats that aggregated Mattiske and Havel's (1998) vegetation complexes.

The subtle variation in vegetation, now well documented in the forests of south-western Australia, has had a profound influence in the variation in disturbance regimes experienced over millennia (Burrows and WardellJohnson 2003). Thus, the maintenance of heterogeneity is fundamental to biodiversity conservation in the fire-prone south-western forested ecosystems. An understanding of historical fire regimes can provide evidence for planning current and future regimes. Wardell-Johnson and Horwitz (1996, 2000) argued that failure to account for subtle differences in vegetation types led to the application of broad-scale regimes of fire, logging and mining that did not reflect previous regimes (for perhaps 40 000-60 000 years) by Aboriginal occupants. There has been much conjecture concerning historical fire regimes in southwestern forested ecosystems (e.g., Hallam 1975, Conacher 1983, Storr 1991, Wardell-Johnson and Horwitz 1996, 2000, Abbott and Burrows 1999, Ward et al. 2001, Abbott 2003, Lamont et al. 2003). We illustrate this debate by examining the case study provided by Ward et al. (2001), and another on the interaction of fire and logging leading to declines in populations of marsupials.

\section{Case study 1: Grasstrees and historical fire regimes}

Studies on grasstrees examined historical fire regimes prior to and following European settlement. Ward et al. (2001) provided an innovative and effective method for ageing Preiss's Grasstree Xanthorrhoea preissii, and determining its fire history over the last 250 years. They found that fires were recorded on grasstrees at 3-5 year intervals prior to 1870 , while contemporary recorded intervals are 10-20 years. They concluded that their methods provide a guide to landscape-scale changes in fire frequency over the same period, and a reconstruction of the fire history

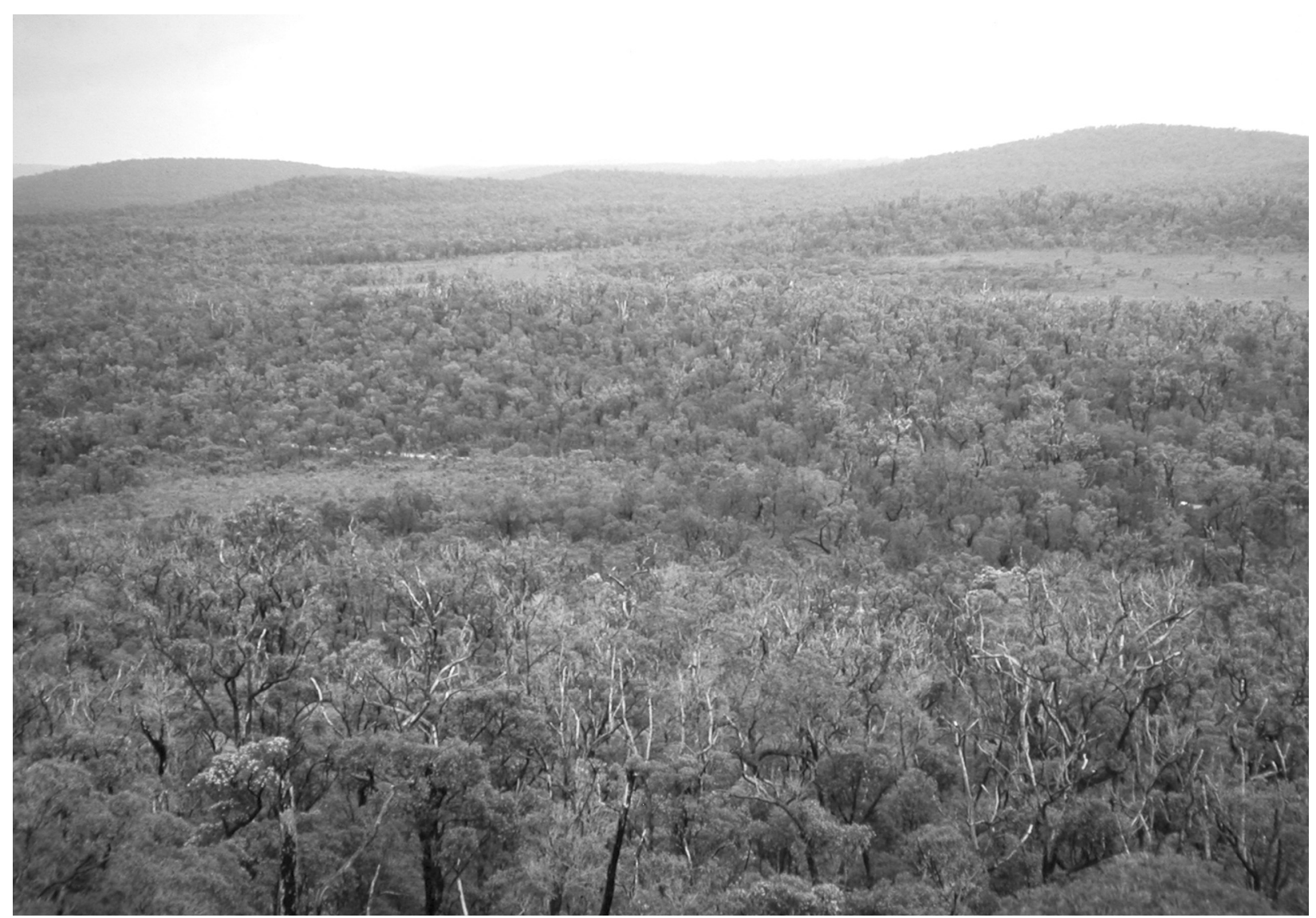

Figure I. Despite subdued landscapes, variation in edaphic features and vegetation patterns can provide barriers that limit the spread of low intensity fires in jarrah forest. Photo Grant Wardell-Johnson. 
of the jarrah forest over the last 250 years (Ward et al. 2001). They also argued that fire incidence on individual grasstrees may represent the fire history of a region, and that their results suggest marked changes in the fire regime of south-western Australia over a short period.

As argued by Burrows and Wardell-Johnson (2003), the evidence for more frequent firing of grasstrees prior to European settlement is compelling. However, frequency is only one component of the fire regime (others being extent, intensity and seasonality, Gill 1981), and the issue of frequency is equivocal without location-specific data. A survey design to allow an assessment of whether the frequencies observed among individual grasstrees were due to landscape-scale fires or the firing of individual grasstrees would require within location replication. Replication and the recording of site data would allow comparison between community types or vegetation complexes. As Ward et al. (2001) did not provide information on the community types, vegetation complexes or defined ecosystems from where they collected their data; it is difficult to check whether their data are relevant to the south-west as a whole. By not doing so, they implied that their data represent the range of environments in which fire occurs within the south-west. This research is important because it would allow explicit recognition of landscape heterogeneity in relation to disturbance. Our concern is that the extrapolation of point-source data on frequency to landscape level patterns of regime makes assumptions concerning homogeneity and determinism that can undermine nature conservation initiatives.
We advocate explicitness, and the integration of a variety of data types and research approaches to understand past fire regimes. Seeking the congruency of various data types as advocated by Kleining and Witt (2001) may thus be appropriate. For example, the evidence from grasstrees could also be combined with evidence from the physical structure of long-lived components of the vegetation and data from the historical record. The presence of peppermints Agonis flexuosa with large boles in coastal dune systems suggests either no fires or low intensity fires in this landscape over a considerable period (Figure 2). This conclusion can be drawn because moderate to high intensity fires often reduce stands of this species to multi-stemmed clumps as it is a vigorous resprouter from lignotuber, but with limited capacity for epicormic shoot production due to its relatively thin bark (Wardell-Johnson 2000, Burrows and WardellJohnson 2003). This evidence in combination with stands of grasstrees displaying regular or frequent fire scars would indicate frequent (low intensity) burning of this landscape over a lengthy period. Similarly, the occurrence of stands of relatively fire sensitive endemic species such as Eucalyptus virginea (ms) in areas of outcrop and along creek lines suggest less frequent fires in some parts of the landscape than others (Figure 3).

That fire regimes (intensity, extent, frequency and seasonality) differed prior to European settlement has been well documented. Low intensity fires have previously been argued as being common-place in jarrah forests before European settlement (e.g. Harris and Wallace 1959, Wallace 1965). For example, Harris and Wallace $(1959$, p2) stated that:

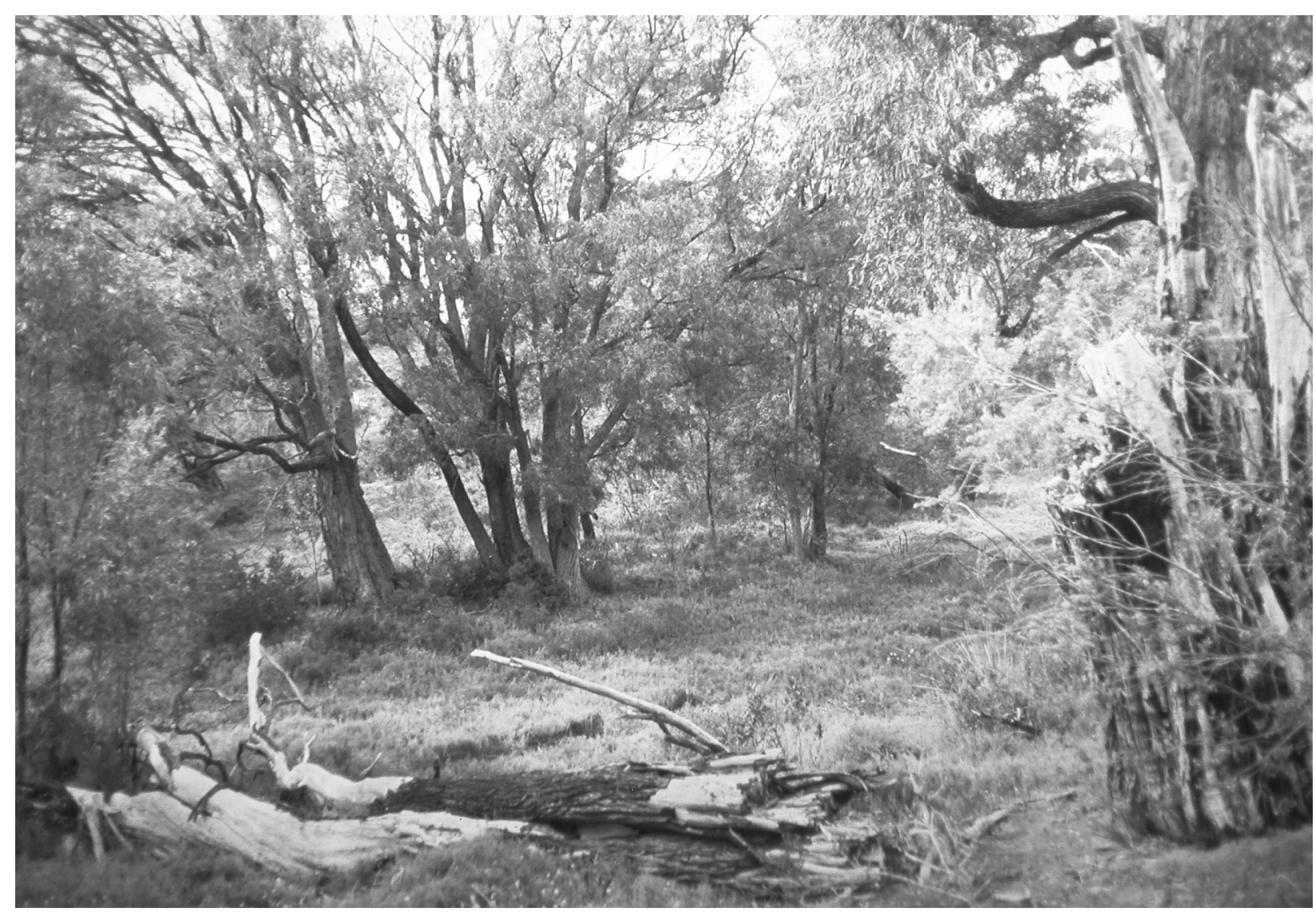

Figure 2. Large-boled individuals of peppermint Agonis flexuosa provide evidence of low intensity fires (or no fires) in aeolian dune systems near Walpole, south-western Australia. photo Grant Wardell-Johnson. 


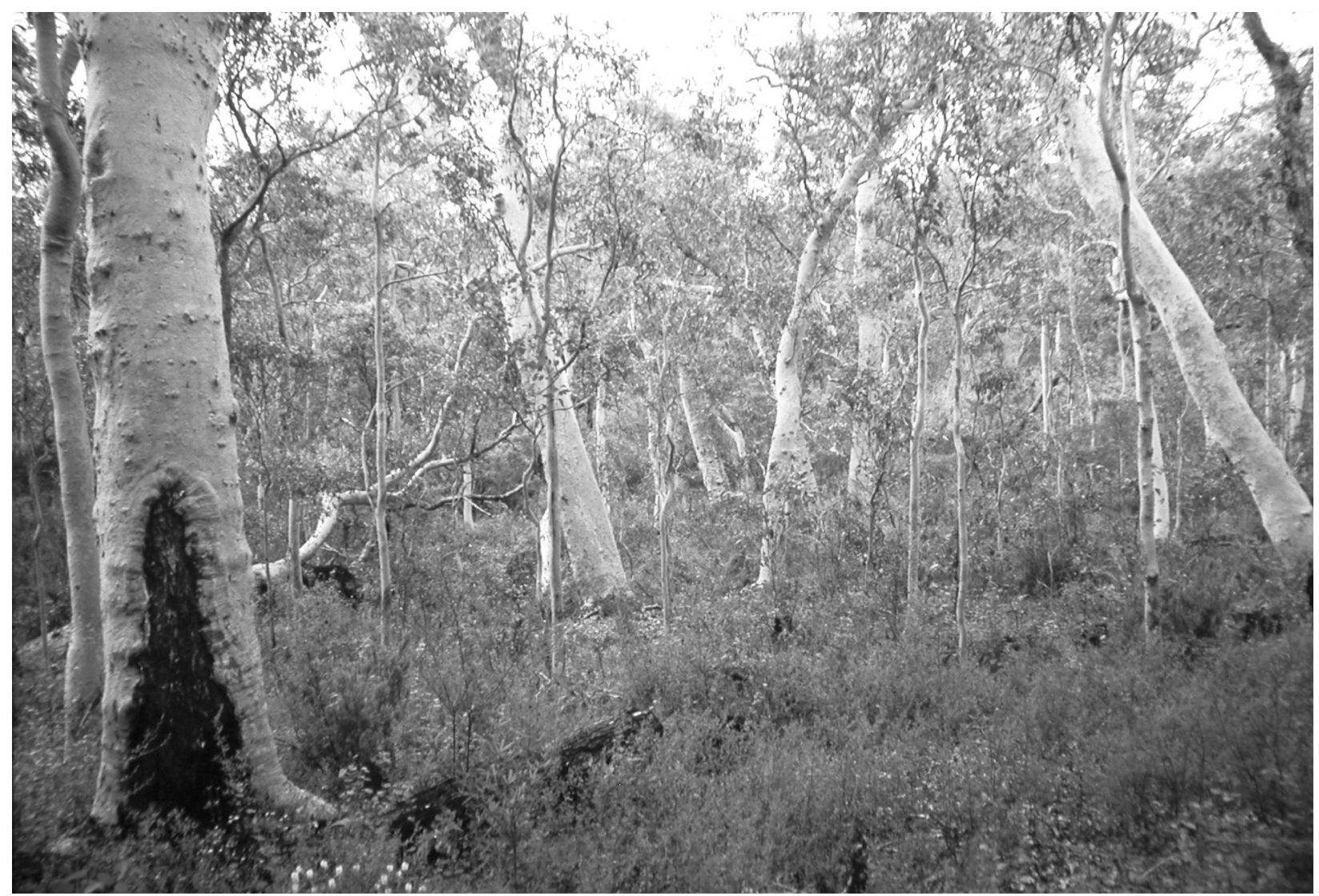

Figure 3. Stand of White's gum Eucalyptus virginea ms, a relatively fire sensitive locally endemic species occurs adjacent to outcrop and along creek lines near Denmark, south-western Australia.

"Since the advent of white settlement in 1829 the forests were progressively subjected to uncontrolled exploitation and this resulted in the accumulation of masses of debris left after felling operations. There was no orderly disposal of these masses of fuel and the result was fires of increasing severity over greater and greater areas. This was a violent contrast to the light periodic fires of past centuries. At the same time, the opening of the closed canopy of the virgin stand produced a considerably heavier growth of ground flora and a marked increase in the understorey trees (Banksia, Casuarina, etc.) which assumed the character of weed growth in the openings. The fuel near the ground was thus increased and had the effect of taking uncontrolled fires into the canopy level. This led to severe crown damage not only in the cut over areas, but in the adjacent virgin forest which was swept by these heavier fires. Damaged crowns slowed down growth and competition for the site and, together with the greater incidence of sunlight at ground level, further increased the density of ground flora and understorey trees. Bole damage became excessive and badly scarred trees and hollow butts are mute reminders of past maltreatment."

From first-hand experience in the 1920s, Wallace (1965, p.34) described low-intensity fires as ones that:

“...could creep for weeks on end, unhindered by anything but a rare shower or an occasional moist gully. With the possibility of a number of fires of this type occurring in the forest area at the same time, it is not unreasonable to assume that the forest was completely burnt through every 2-4 years. ... These fires were alight in December and continued to burn until the following March, increasing in intensity as hot weather developed and waning to a faint smoke on the cooler days, until finally extinguished by steady rain. ... Flames from these light fires could have been no more than $1-3$ feet high, in the limited fuel available, and caused little damage to the trunks of the trees and the crowns towering high above them."

Such fires burning in a low fuel load tend to cover the landscape unevenly, with intensity influenced by factors such as vegetation, moisture slope and prevailing weather conditions, with areas left unburned within the general area of the fire (Burrows and Wardell-Johnson 2003, McCaw and Hanstrum 2003). Thus they reduce the risk of more severe fires in heavier fuel loads, while leaving unburned refuges for fauna. However, it should be noted that the observations reported by Wallace (1965) for the 1920s were considerably later than the general displacement by Nuyngar people in the area. Hence, while low intensity fires may have been the norm, during Nuyngar occupation, there remains the issue of scale and approach to implementation.

Both number of fires and time-since-fire are important discriminators of floristic pattern (Watson and WardellJohnson in press). Similarly, landscape-scale fires burnt at the same interval may have a very different affect on the biota than small-scale patch burning at frequent intervals. Small-scale patch burning has been implicated 
in the conservation of medium-sized mammals in the semi-arid and arid zones of Australia in the context of Aboriginal land management practices (Burbidge and McKenzie 1989). These authors were able to argue that the demise of medium-sized mammal fauna from desert regions of Western Australia followed the change in fire regimes from relatively frequent low-intensity patch burning to broad-scale intense fires. In turn this change in fire regime had accompanied the decreased presence of Aboriginal people in the area. The general occurrence of low intensity patch burning has also been documented in the high rainfall forested environments managed by Kuuku ya'u people of north-eastern Cape York (Chase and Sutton 1981, Hynes and Chase 1982).

It is also possible that low-intensity patch burning was commonplace in many jarrah forest environments managed by Nuyngar people. This would have resulted in different outcomes for fauna than frequent broad-scale fires of similar intensity. This is because of the changes in weather patterns occurring over the period when fires will burn in jarrah forest communities, and hence the reduced likelihood of retaining low intensities into the summer period (see McCaw and Hanstrum 2003). Thus, the predictability of where refuges are likely to be retained is reduced by broad-scale, rather than by fine-scale patch burning. McCaw and Hanstrum (2003, p 103) highlight outcomes for heterogeneity in the context of Aboriginal burning.
"Fires burning over an extended period may exhibit a wide range of intensity as a result of variation in weather conditions, slope, fuel moisture, and vegetation type. The age and condition of the vegetation and fuels also has a profound effect on fire behaviour and the resulting mosaic of environmental effects. Forest and shrub fuels that have been unburnt for 8 years or more can support an intense fire under dry summer conditions, with little or no chance of leaving substantial patches unburnt within the fire perimeter. In contrast, fires burning in forest fuels that are less than 3 yrs old and shrub fuels that are less than 5 yrs old tend to result in a heterogeneous mosaic of burnt and unburnt patches, unless the fire weather conditions are extreme . . . Eucalypt woodlands in drier parts of the south-west may take decades to accumulate sufficient fuel to sustain a fire, with the pattern of previous fires having a profound influence on current opportunities for fire spread in the landscape.

The periodic burning practiced by Aborigines over much of south-west WA ... would have tended to favour heterogeneity in vegetation structure and fuel age, as well as limiting the opportunity for large scale fire events."

We therefore argue that it is inappropriate to imply the transfer of point-based data of frequent fire derived from grasstree records to regimes for the community

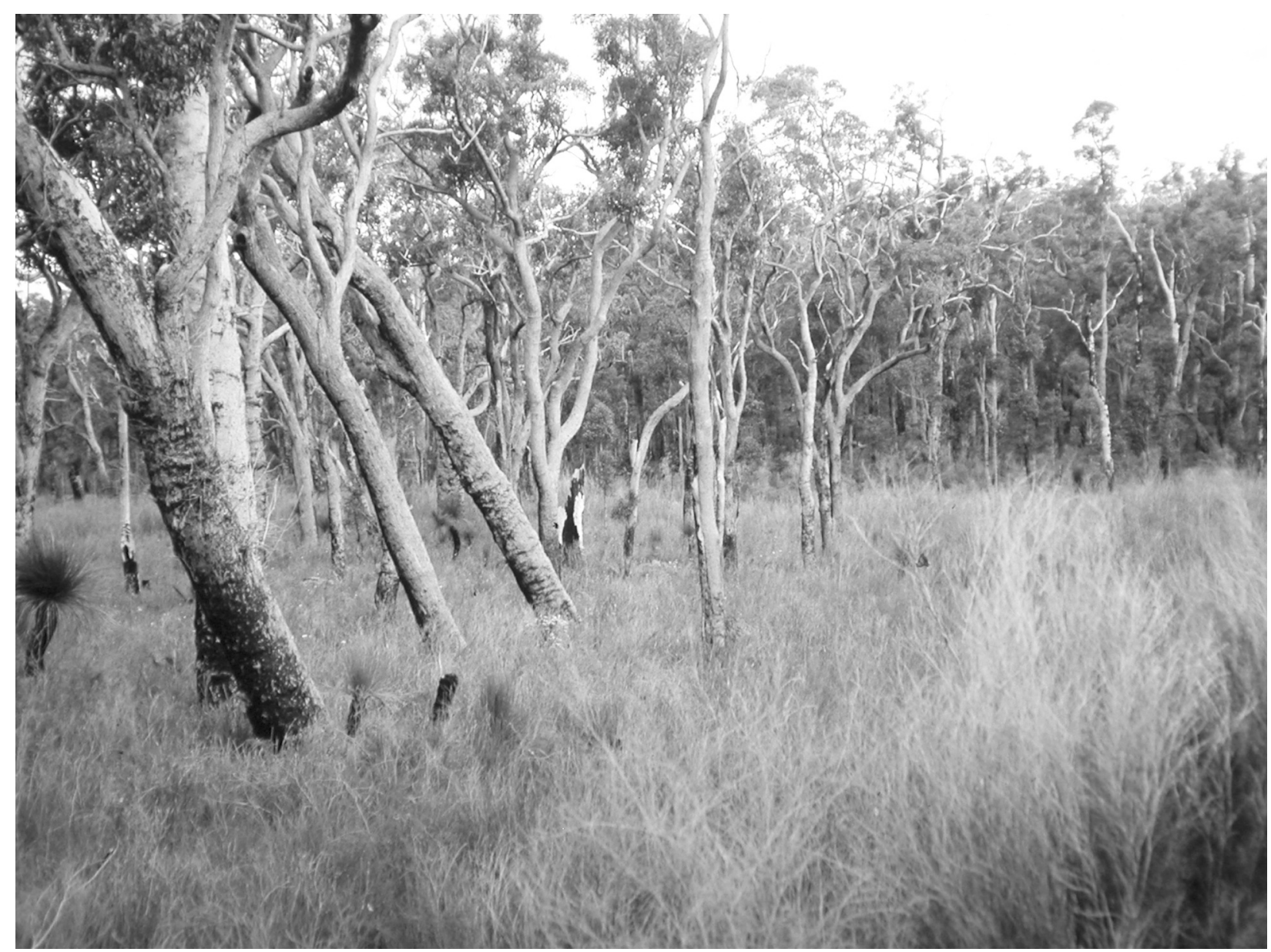

Figure 4. Variation in fuel types in adjoining peat swamp and jarrah forest habitat limits substrate ignition during low intensity fires. photo Grant Wardell-Johnson. 


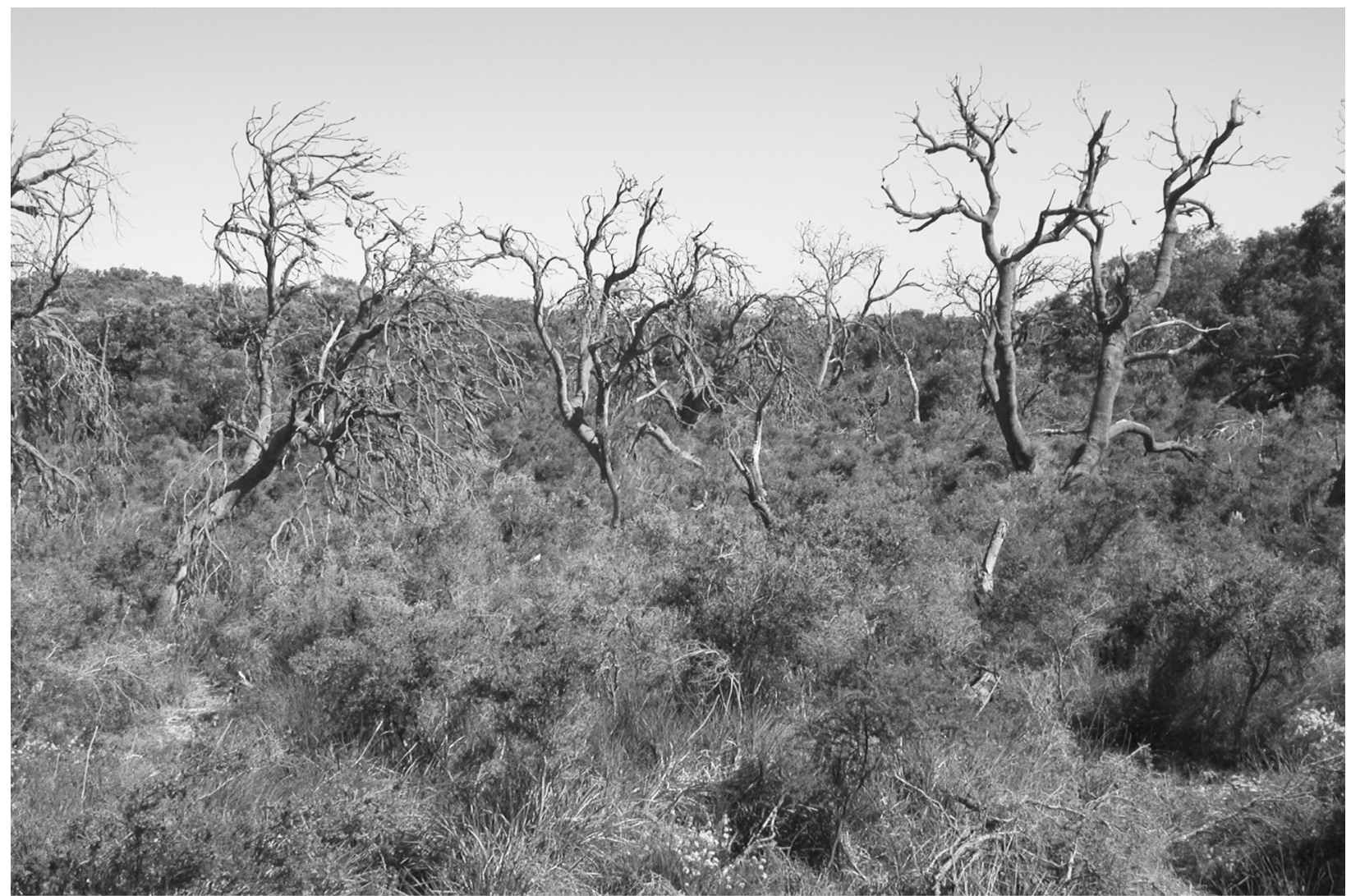

Figure 5. Changes in vegetation following the spread and intensification of dieback Phytophthora cinnomomi, in jarrah/ Banksia woodland on aeolian sands near Busselton, south-western Australia. Photo Grant Wardell-Johnson.

types of a region. Frequent firing of certain parts of the landscape does not imply patterns of regime across the entire landscape, or patterns of ignition. It is possible that within south-western Australia, some vegetation types were at times burnt frequently (e.g., the Agonis woodlands that have now become thickets in the absence of fire on the south coast in a similar way to documented examples in north-eastern Cape York Penninsula - see Chase and Sutton 1981), and at a fine patch scale.

However, other areas may have been protected from fire - possibly through active fire exclusion by Nuyngar people. This would have ensured the protection from fire of particular vegetation types or specific components of the landscape. For example, in south-western Australia, evidence of ancient, deep and highly combustible peat swamps surrounded by jarrah forests (Horwitz et al. 1999, Horwitz et al. 2003) demonstrates a different fire regime in historic times for neighbouring community types. This may be due either to a changed climate increasing the likelihood of these peat deposits drying and hence burning in recent times. Either this, or if parts of the surrounding landscape were burnt frequently, then a protection strategy was in place to prevent the burning of these components of the landscape in an environment of frequently occurring fires. This may have included the use of wind-driven fires when the substrate is damp (Figure 4). Thus variation in fuel types may be a factor in fire control in the context of low intensity fires. It is possible that broad-scale patch-burning was carried out frequently in an environment of low fuel loads leading to heterogeneity in fire and landscape interactions. Scale and pattern as well as frequency would have been important considerations in planning for such regimes (Burrows and Wardell-Johnson 2003). Thus, there is a need to define the components of the regime and scale under consideration, and confine conclusions to the relevant parts of landscapes.

\section{Interactions between fire and other disturbance agents}

Many forms of disturbance have provided forces of evolutionary significance in the south-west prior to European or Aboriginal settlement (Burrows and Wardell-Johnson 2003). However, the intensity and extent of some of these influences have been considerably exacerbated, and many new forms of disturbance have occurred since European settlement (Mills 1989, Havel 1989, Wardell-Johnson and Nichols 1991, Burrows and Wardell-Johnson 2003, Calver and Wardell-Johnson 2003). For example, Figure 5 demonstrates changes associated with the introduction and intensification of dieback caused by Phytophthora cinnamomi in jarrah/ Banksia woodland on aeolian sands, while Figure 6 provides a photographic synthesis of the recent history of disturbance in a lateritic site in the northern jarrah forest. Burrows and Wardell-Johnson (2003) argued that the interactions between various agents of disturbance might be of greater importance in nature conservation than the impacts resulting from any particular event. For example, links have been hypothesized between plant disease, introduced species, fire and logging (e.g., Shearer and Tippett 1989, Wardell-Johnson and Nichols 1991, Young 1994, Garkaklis et al. 2003). Interactions between 


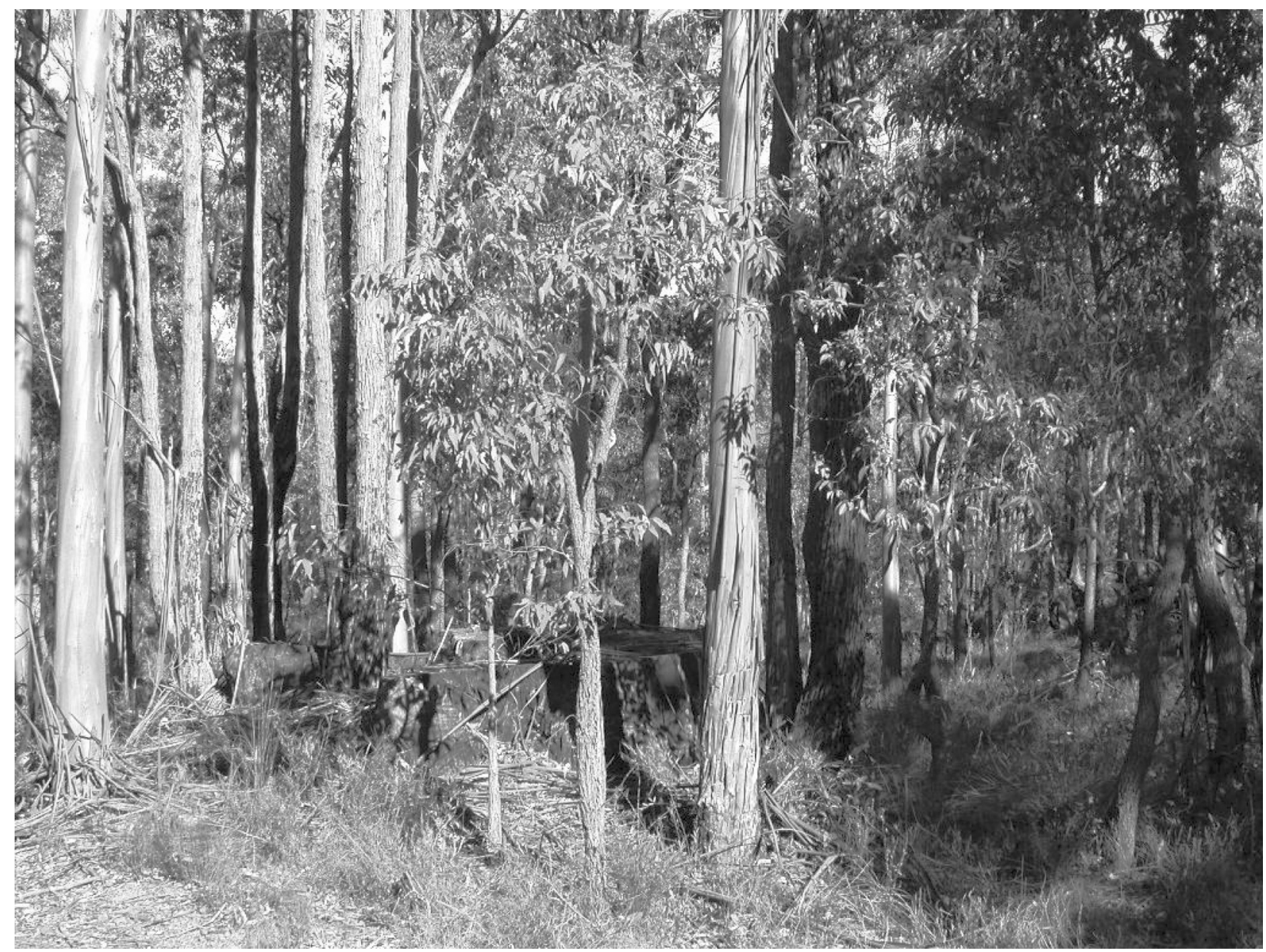

Figure 6. Large remnant jarrah stump in rehabilitated 'dieback graveyard' site near Dwellingup, south-western Australia. photo Grant Wardell-Johnson.

disturbance regimes such as fire and the establishment of introduced species also have conservation consequences (e.g., Bond and van Wilgen 1996). Burrows and WardellJohnson (2003) concluded that introduced plant invasions can be a potential conservation threat through direct displacement of native flora and fauna or by altering the fire regime in some sites. The same argument can be applied with respect to introduced fauna. We examine interactions by considering a case study of fire, marsupial fauna and the Red Fox in south-western Australia.

\section{Case study 2: Changing fire regimes with implications for the marsupial fauna of the Jarrah forest}

The widespread declines of marsupial species across the south-west of Western Australia have been attributed to a range of factors including habitat clearing, changed fire regimes, exotic disease, logging impacts and exotic predators (Calver et al. 1998). Exotic predators, especially the Red Fox, are now accepted as an important cause (see Morris et al. 1995, Morris et al. 2000 and Kinnear et al. 2002 for empirical evidence specifically related to southwest Western Australia). However, foxes did not reach Western Australia until 1912 and were not widespread in the forested regions of the south-west until the 1930s (Kinnear et al. 1988). Shortridge (1909) and Woodward (1909) noted that declines in Western Australian marsupials began before these times. Shortridge (1909, p.819), writing of collections made between 1904 and 1907, specifically observed that:

"The mammals of the South-West, to almost as far north as the Moore River, have not disappeared in the same extraordinary way, although they are rapidly retreating before civilisation, being already very rare to the north of the thickly populated districts around the Swan River, as well as around all the settledin and agricultural areas. The burning of forests and general clearing of the country, together with constant raids of dogs and domestic cats, are among the chief causes."

In a later commentary on the same collections Shortridge wrote:

"(The mammal fauna of Western Australia is definitely vanishing, many species being already (1907) on the verge of extinction. In the north-west (mainland) and the interior native rodents and the smaller marsupials have for the most part completely died out, while in the south-west a few remote inland and coastal forest regions appear to be their last strongholds. This disappearance has been ascribed to several causes: - epidemics, bush fires, cats that have run wild, the spread of imported house mice, \&c.)" Shortridge (1936, p.746) 
The observations of Shortridge (1909, 1936) and Woodward (1909) for fauna declines before the Red Fox points to a combination of causes for the overall pattern of decline. Recent modelling indicates that fire and predation by foxes can be interactive in their impacts on small mammal populations, presumably because fire may reduce cover for prey (McComb 1994). Here we explore the possibility that changed fire regimes contributed to the early $20^{\text {th }}$ century declines in the marsupial assemblage in the jarrah forests and that fire and predation by foxes exerted interactive impacts after the 1930s.

The marsupial fauna of the jarrah forest declined substantially during the $20^{\text {th }}$ century such that by the 1970 s only a few forest sites retained most of their marsupials (see Davey and Norton 1990, Wardell-Johnson and Nichols 1991). For example, by the 1970s the Brush-tailed Bettong Bettongia penicillata ogilbyi, known locally as the Woylie, the Western Ringtail Possum Pseudocheirus occidentalis, and the Quokka Setonix brachyurus (Figure 7) had been lost from the bulk of their pre-European settlement habitat while the Chuditch Dasyurus geoffroi had declined to almost undetectably low densities by the early 1980s and the Bilby Macrotis lagotis had been lost from the jarrah forest faunal assemblage (McKenzie et al. 1996, Abbott 2001). The Perup Forest near Manjimup on the eastern margins of the forest belt is the most important region to retain a diverse marsupial assemblage (e.g., Davey and Norton 1990) and both the Perup Forest itself and the adjoining Greater
Kingston region are sites of important recent studies on marsupial ecology in the south-west (e.g., Rhind 1998, Scarff et al. 1998, Morris et al. 2000). Could changed fire regimes following European settlement have contributed to marsupial decline in the jarrah forest?

As suggested by the personal observations of Wallace (1965), low intensity fires are believed to have been common in jarrah forests before European settlement (see case study 1). Frequent ignitions across the landscape in circumstances of a low fuel load will leave many areas left unburned within the general landscape (Burrows and Wardell-Johnson 2003, McCaw and Hanstrum 2003). Thus they reduce the risk of more intense fires in heavier fuel loads, while leaving unburned refuges for fauna.

With regard to fires at higher intensity, Burrows et al. (1995) sampled fire scars on jarrah stumps at 14 sites throughout the jarrah forest, providing a valuable quantitative data set about the frequency at which jarrah boles were damaged by fire both before and after European settlement. The scars counted represent intense fire events, because healthy jarrah boles generally remain undamaged by low intensity fire except where scars form as a result of logs lying close to standing trees. The frequency with which the sampled sites acquired fire damage from intense fires was lowest in what Burrows et al. (1995) called the Aboriginal era (1613 - 1855) when fire injury rates were 0.0008074 injuries/tree/year. They then increased by up to a factor of 10 throughout the

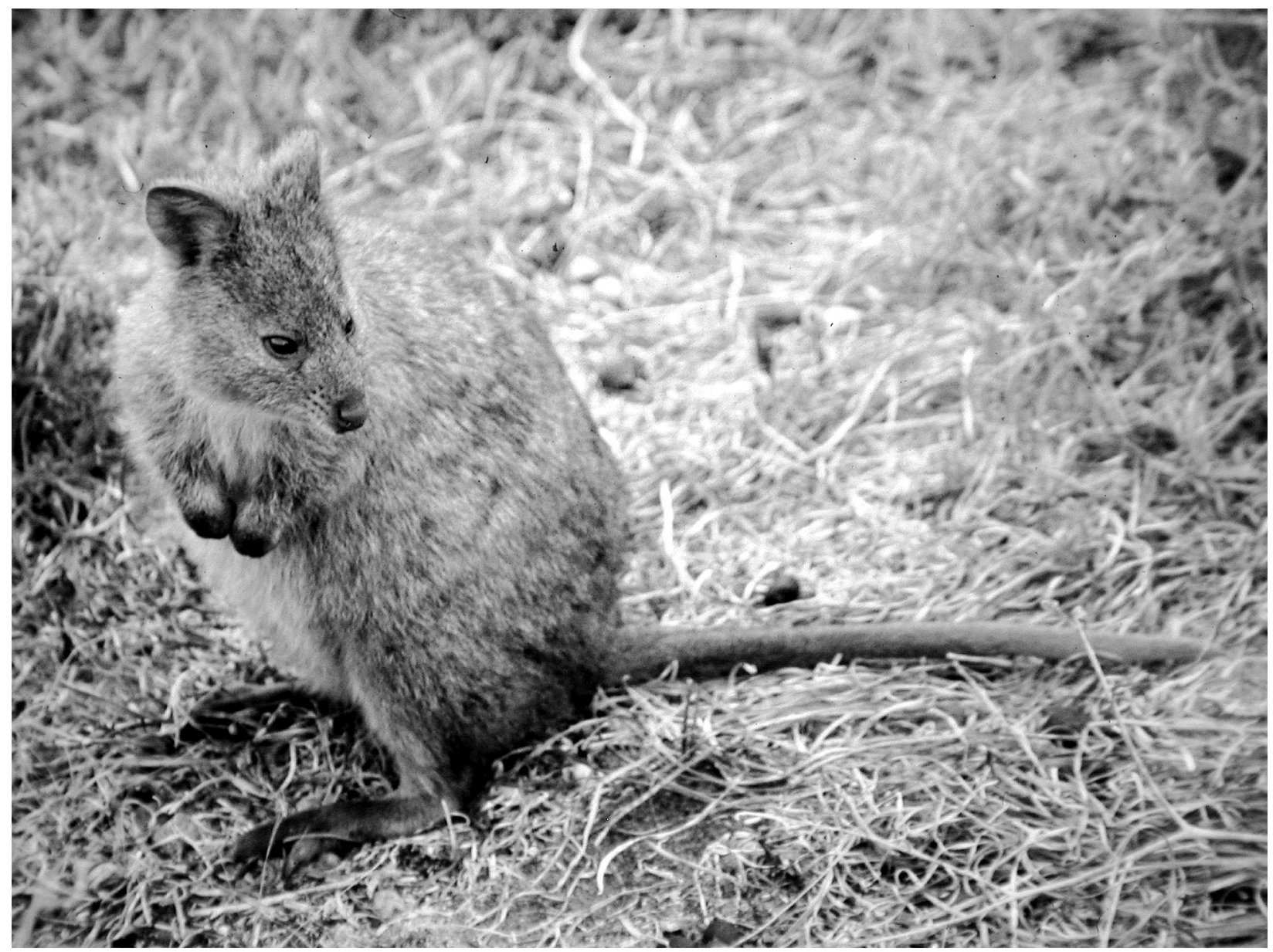

Figure 7. The Quokka Setonix brachyuris is a vulnerable species lost from the bulk of its pre-European settlement jarrah forest habitat during the $20^{\text {th }}$ century. Photo Grant Wardell-Johnson. 
European eras of the late $19^{\text {th }}$ century and the $20^{\text {th }}$ century, while the interval between intense fires decreased from an average interval of 81.6 years during the Aboriginal era to between 13.4 and 22.3 years during the European eras.

There was also a change in the relationship between frequency of intense fires and rainfall between the Aboriginal and the European eras. In the Aboriginal era, before the intensification of European impacts, there was a significant Spearman's rank correlation between rainfall and frequency of intense fires at the sites studied $\left(R_{S}=0.618, p=0.018\right)$. Thus higher rainfall areas produce greater fuel loads, and hence are susceptible to a greater intensity of fire (though the insulating effects of vegetation also produce lower frequency of fires see Christensen and Annells 1985, Burrows and Wardell-Johnson 2003). However, this relationship ended following intensification of European land use between 1855 and 1989, with the sum of the frequency of intense fires for all European eras at the sites studied no longer correlating significantly with rainfall $\left(\mathrm{R}_{\mathrm{S}}=0.290, \mathrm{p}=0.314\right)$. Although individual sites may be exceptions, lower rainfall areas burned with similar frequencies of intense fires as the higher rainfall areas during the European eras. Thus, the data in Burrows et al. (1995) illustrate three general points for the parts of the jarrah forest sampled by those sites: (i) during the Aboriginal era intense fires were rare, (ii) the frequency of intense fires increased following displacement of Aboriginal people and the beginning of European land uses, and (iii) the combined European eras delivered intense fires more uniformly across the landscape, as noted by the absence of the relationship between fire frequency and rainfall noted for the Aboriginal era.

Accumulations of logging debris, especially in productive, high rainfall areas, and the increase in understorey growth when the forest canopy was opened by logging were largely responsible for the intense fires (Harris and Wallace 1959, Wallace 1965, Burrows et al. 1989). Wallace (1965) observed that litter fall in virgin jarrah forest was estimated at one ton per acre per year, whereas early logging operations added between 20 and 30 tons of debris per acre after initial felling while reducing the canopy by $50 \%$ and encouraging understorey growth. This contributed to intense fires "of holocaust proportions" (Anonymous 1970, p.5) "far more intense and devastating than had ever been experienced", McCaw and Burrows 1989, p.318) and of "violent contrast to the light periodic fires of past centuries" (Harris and Wallace 1959), which "caused complete defoliation and great damage to those trees remaining on the area" (Wallace 1965, p.36). Harris and Wallace (1959) and Wallace (1965) noted that virgin forest adjacent to logged sites was also severely burned, while Stoate and Bednall (undated) reported that sawmillers' fires escaped into virgin forest, degrading the canopy, raising water tables and replacing paperbark (Melaleuca sp.) flats with swamps. Wallace (1965) quantified the magnitude of such wildfires by comparing the progress of the Dwellingup wildfire of 1961, which covered 15 miles in 15 hours, with that of a creeping fire believed

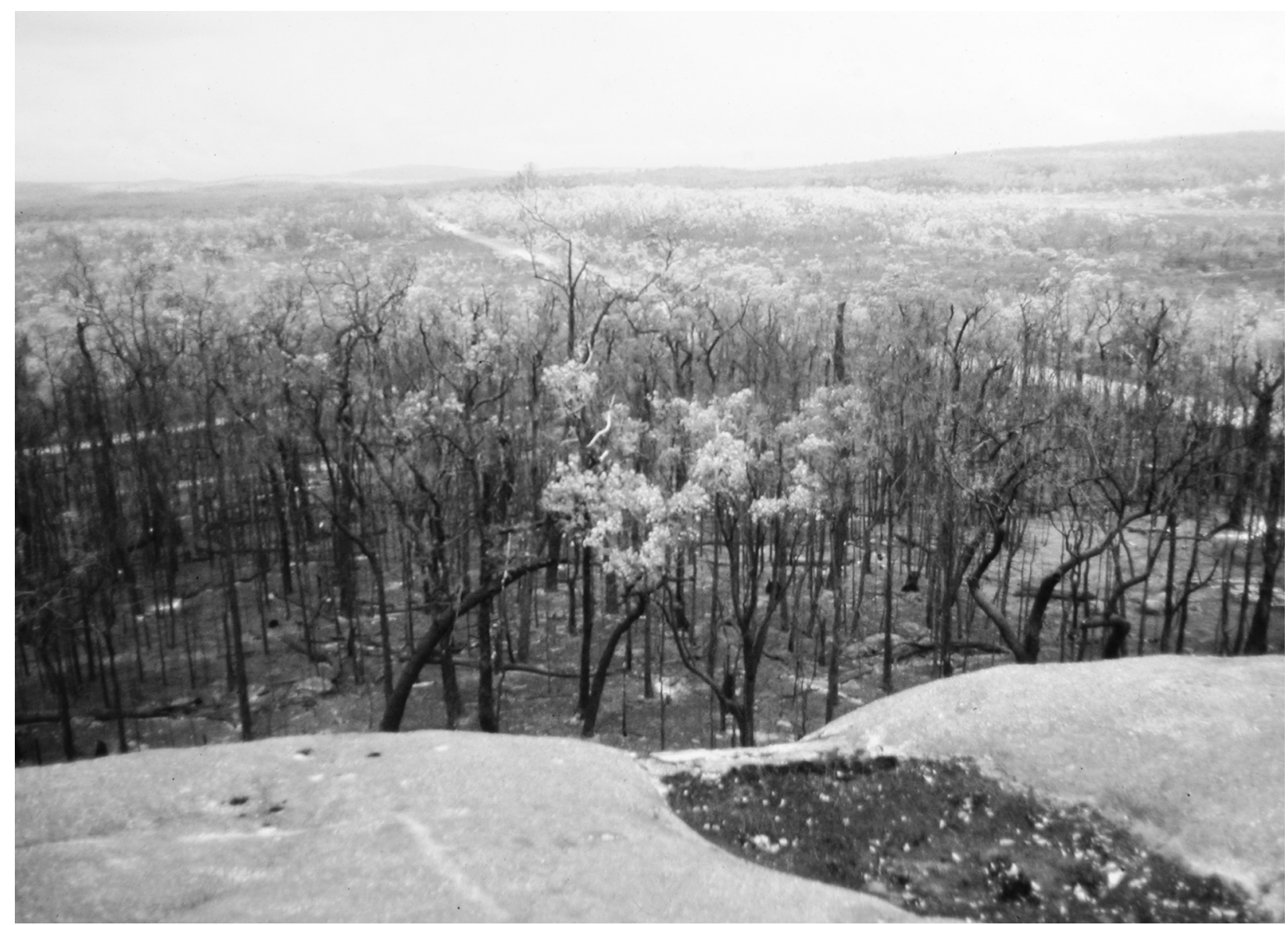

Figure 8. The immediate aftermath of a moderate to high intensity fire in jarrah forest of south-western Australia. Such fires have the capacity to damage tree crowns, leave few unburnt remnants, and have a serious impact on fauna. Photo Grant Wardell-Johnson. 
typical of pre-European fire regimes which covered 15 miles in 3 months. Fires of high intensity (Figure 8) can damage tree crowns, leave few unburned remnants, and have had a serious impact on fauna.

The Perup forest region, which retained a diverse marsupial assemblage throughout the changed fire regimes of the $20^{\text {th }}$ century, lies at the less productive south-eastern margin of the jarrah forests and was not logged until well into the twentieth century (Heberle 1997), after regulatory steps had been taken to reduce the fuel load remaining after logging (Harris and Wallace 1959, Wallace 1965). We contend that the Perup therefore suffered less severely from the increased frequency of destructive fires characteristic of the European eras and that this is an important factor in its retention of a diverse marsupial assemblage.

Other authors, such as Christensen (1980) and Abbott and Christensen (1994), explain the persistence of marsupial populations in the Perup in terms of lower predation by foxes. Sites that retained high mammal diversity were held to be protected by the presence of the plants Gastrolobium spp. and Oxylobium spp. which produce the toxin fluoroacetate (see Buchanan and Wardell-Johnson 1994). Indigenous marsupials were protected from fluoroacetate by a tolerance arising from long co-evolutionary association, whereas foxes were poisoned when eating native animals with toxic plants in their digestive tracts (Twigg and King 1991). However, this explanation does not preclude the probability that changed fire regimes involving an increase in fire intensity, frequency and evenness in distribution across the landscape in the $19^{\text {th }}$ and $20^{\text {th }}$ centuries was a substantial initiating factor in the $20^{\text {th }}$ century contraction of the jarrah forest marsupial fauna. Following this initial decline, predation by foxes had a major detrimental impact on remnant marsupial populations persisting in habitat refugia and posed the most immediate and treatable threat to them.

\section{Implications of the landscape case studies}

These two case studies can be interpreted to indicate the likelihood of fine-scale heterogeneity in disturbance patterns on the landscape as argued by Wardell-Johnson and Horwitz (1996, 2000), and demonstrated using the Roseat Frog Geocrinia rosea complex as an exemplar (Wardell-Johnson and Roberts 1993, Driscoll 1998). Extrapolating from site-based data on frequency to convey landscape-scale regimes such as that outlined by Ward et al. (2001), obscures fine-scale heterogeneity in disturbance that is critical to the conservation of biodiversity. It will be necessary to integrate data from a range of disciplines and seek congruency of various data types (see Kleining and Witt 2001) to enable understanding of historical fire regimes. Requirements for integration will become more critical with the accelerated pace of change predicted as a result of anthropogenic climate change (Hughes 2003).

The assessment of proximate and ultimate causes of marsupial decline as illustrated by case study two indicates that disturbance arising from resource use may simplify natural patterns of disturbance across a landscape, possibly reducing the habitat variegation important for maintaining fauna species richness. Thus, marked post-European changes to fire regimes were interactive with logging, leading to changes in the intensity and frequency of fire that applied more uniformly than before across the landscape. Fauna declines arising from this would be evident before foxes reached the south-west of Western Australia. More detailed assessments of fire history in areas where fauna have been lost before Red Fox introductions and areas of strong fauna persistence, especially a check for the history of intense fires in the Perup, could allow the testing of the hypothesis. Integrated, all strands of evidence point to the importance of management at a fine scale and an understanding of both proximate and ultimate causes of decline. Concentrating on proximate causes of fauna decline such as the presence of introduced predators produces immediate conservation gains. However, long-term conservation also requires an understanding of the ultimate causes such as clearing, and changing stand structure to allow the establishment of predators. Furthermore, interactions between disturbance agents are likely to have greater impacts than the individual impacts of any one factor.

Regardless of these historical patterns, the considerable changes wrought by Europeans on the Australian landscape (e.g. clearing, exploitation, fragmentation, introduction of plants and animals - Figures 5, 6) make attempts to restore historical regimes both problematic and, arguably, inappropriate. Future regimes will be influenced by many new factors such as settlement patterns of people, public health, the presence of introduced species, and climate change (see Hughes 2003), regardless of earlier regimes. It is also necessary to examine individual species studies to explore environmental nuances for management actions. It is to particular species population studies that we now turn.

\section{Population and autecological studies}

Despite the increasing emphasis on processes such as fire and predation at the landscape-scale in conservation biology (e.g. Turner et al. 1994, 1995, Gardner et al. 1996), until recently only limited data were available on the responses of species to disturbance in the jarrah forest. However, species studies are essential for effective conservation outcomes in the face of landscape-scale change (e.g. Wardell-Johnson and Roberts 1993, Driscoll 1998). Many threatened fauna species are known in the Jarrah Forest Bioregion and many approaches can be used to prioritise taxa for study, including the focal species approach (e.g. Lambeck 1997, Watson et al. 2001). In the face of a broadscale timber industry, many initiatives have been taken in relation to hollow-nesting species in the jarrah forest. These have been summarised by Stoneman et al. (1997), and include an extensive network of reserves, retention of habitat trees, stream and road reserves and the staggering and dispersion of logging coups. This activity reflects the considerable controversy surrounding fauna conservation, especially of hollow-using fauna. We seek to examine the information base available for management planning for fauna conservation, and consider the issues of risk assessment, appropriate methodologies and understanding of logging impacts on particular species in the jarrah forest. While a discussion of the conservation of hollow-using fauna is at the core of the argument, we also consider a local case study using population viability analysis (PVA) to provide an example of one method for addressing population changes in vulnerable taxa. 


\section{The conservation of hollow-using fauna}

The arguments concerning vulnerable, indicator or focal fauna (e.g. see Lambeck 1997, but also Lindenmayer et al. 2000) of the jarrah forest are illustrated most clearly in the complex of issues involving conservation of hollow-using fauna in the presence of an extractive timber industry. Forty-two species of vertebrate are known to use tree hollows for breeding or shelter in the forests of Western Australia (Abbott and Whitford 2002), including the Rufous Treecreeper Climacteris rufa (Figure 9), suggested by Williams et al. (2001) as being a useful indicator species for impact studies. However, detailed studies of the abundance and distribution of the hollow resource and its use by fauna only began in the late 1980s, focusing principally on jarrah and marri. Key studies include those of Inions et al. (1989), Jones et al. (1994a,b), Jones and Hillcox (1995), Rhind (1996) and How and Hillcox (2000) on use of den trees by possums, McComb (1994) on use of tree hollows by the Australian Ringneck Platycercus zonarius and Common Brushtail Possum Trichosurus vulpecula, Mawson and Long (1994) on the use of hollows by birds, Faunt (1992) and Williams and Faunt (1997) on hollows in fallen logs, Rhind (1996, 1998) on den tree use by Brush-tailed Phascogale Phascogale t. tapoatafa, Abbott (1998) on hollow use by the Forest Red-tailed Black Cockatoo Calyptorhynchus banksii naso, Whitford and Williams (2001) on the longevity of designated habitat trees and Whitford (2001, 2002) and Whitford and Williams (2002) on the distribution and abundance of hollows and selection of habitat trees for hollow-using fauna.
Faunt (1992) and Williams and Faunt (1997) found that the occurrence of hollows in fallen logs suitable for ground-dwelling mammals was associated with log size, fire damage, decomposition and termite attack. McComb (1994) assessed data on fallen logs from approximately 2800 ground plots (each $0.12 \mathrm{ha}$ ) across the northern jarrah forest region as potential habitat for Chuditch. Logs with a hollow in the centre only, a hollow entrance $>7 \mathrm{~cm}$ diameter and a hollow depth $>80 \mathrm{~cm}$ were considered potential den logs and areas with at least 0.12 potential den logs/ ha were considered suitable habitat. Although there was considerable variation in the number of potential den logs across the region, only areas of low-quality mature jarrah, and sites cleared, mined and rehabilitated following bauxite mining fell short of the minimum required density. Therefore the fallen log resource appears adequate for Chuditch in most areas, but no account is taken of possible competition between Chuditch and other species such as the Numbat Myrmecobius fasciatus, and the Common Brushtail Possum. It is possible that in some areas, logging has increased the available hollow resource for terrestrial hollow users such as the Numbat as argued by Christensen et al. (1984) in the Perup. However, this may be at the expense of hollows in standing trees.

Studies of hollows in standing trees were more contentious because of methodological controversy concerning counting hollows and ageing hollow-bearing trees. McComb (1994) and Rhind (1996, 1998) used a mixture of assessing hollows in felled trees and counting hollows from the ground, whereas Whitford (2002) examined hollows in felled trees.

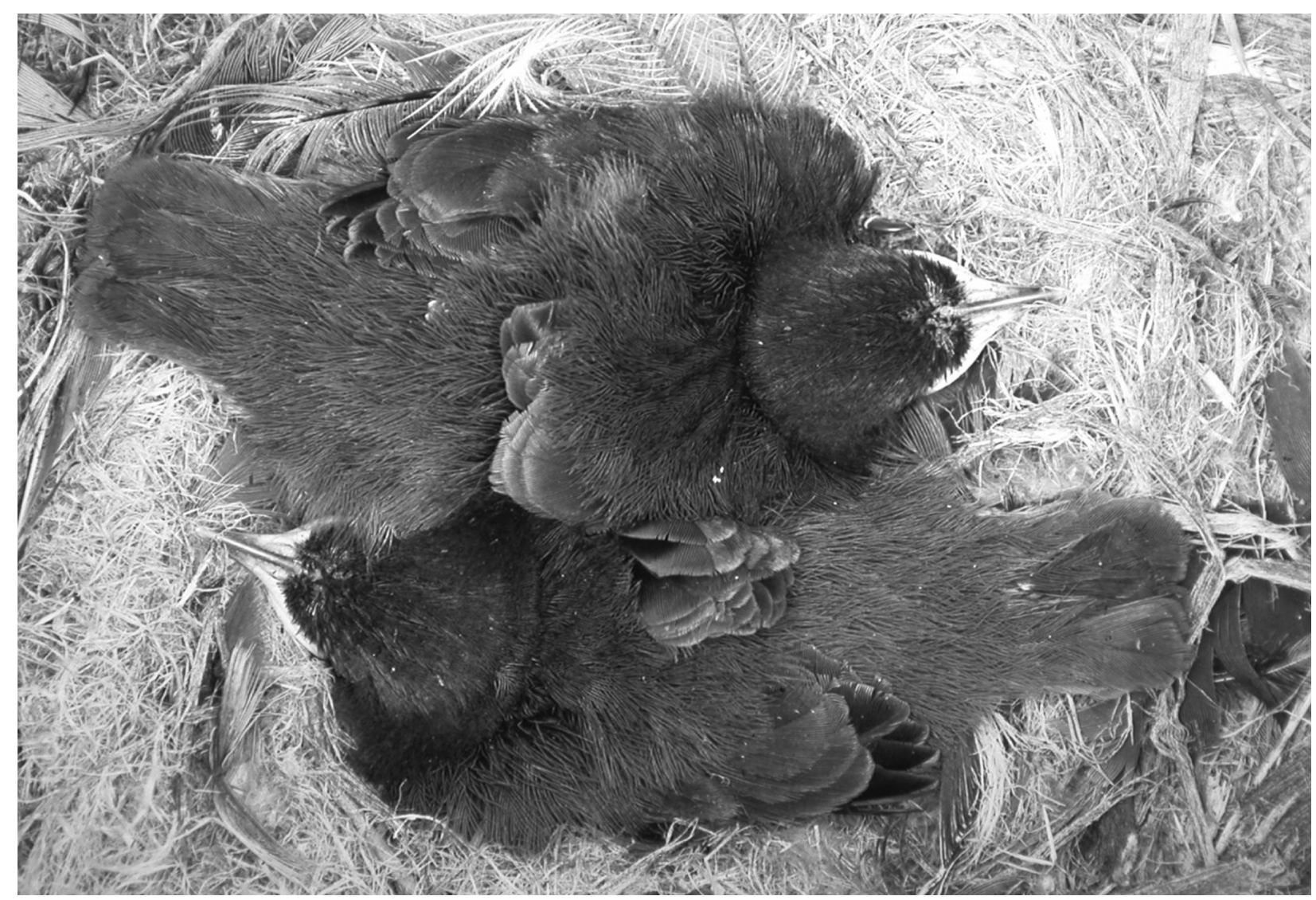

Figure 9. Nest of Rufous Treecreeper Climacteris rufa, one of several vulnerable hollow-nesting species occurring in the jarrah forests of south-western Australia. Photo Grant Wardell-Johnson. 
Although the two measurements correlated significantly, $\mathrm{r}^{2}$ was only 0.32 , so Whitford (2002) concluded that counting hollows from the ground was an unreliable indicator of hollow abundance. Instead, Whitford and Williams (2002) recommended using tree size and crown condition as nondestructive predictors. This is sound advice, although we do not believe it precludes using existing data based on counts from the ground for comparing the relative incidence of hollows in different stands rather than assessing absolute abundance. Whitford (2002) and Whitford and Williams (2002) also aged the felled trees in their samples by ring counts, finding that the estimates of tree age used by several earlier authors were likely to have been too great.

Synthesising the results, the largest trees held the greatest number of hollows and were more likely to contain large hollows suitable for use by larger fauna (Inions et al. 1989, Mawson and Long 1994, McComb 1994, Whitford 2002). However, small trees were more numerous and did contribute a significant number of hollows, especially for smaller animals (Whitford 2002). Marri contributed more useable hollows per tree than jarrah (Whitford and Williams 2001), mainly because marri hollows are frequently deeper and wider than jarrah hollows of similar entrance dimensions (Inions et al. 1989, Whitford and Williams 2001). Whitford (2001) and Abbott and Whitford (2002) provided estimates of the minimum hollow dimensions required by a wide range of vertebrates, and the size or age of trees likely to contain them. Many of the mammals used multiple hollows, and not all trees with suitable hollows for a species were used. For example, the Brush-tailed Phascogale used an average of 27 hollows (males) and 38 hollows (females) per year of adult life (Rhind 1998) and the Western Ringtail Possum used 3-8 den trees per year (Jones et al. 1994b). Inions et al. (1989) reported that approximately half of den trees suitable for the Common Brushtail Possum were not used, demonstrating that hollow selection may be complex. A recent risk assessment of hollow-using fauna in the southwest identified no species currently at high or immediate risk of decline, but called for further modelling of stand structure and detailed ecological studies of selected hollowusing species to substantiate the predictions (Abbott and Whitford 2002).

While the abundance and distribution of hollows is now better understood, knowledge for its effective application in conservation management remains at a cursory level (Gibbons and Lindenmayer 2002). In south-western Australia, studies on the formation and use of hollows have considered the quantity of hollows and their entrance size and interior dimensions (e.g. Abbott and Whitford 2002), while others have focused mainly on tree age and crown condition (Whitford and Williams 2002). While tree size, age and crown condition can give a good estimate of the availability of hollows (Whitford and Williams 2002) they still do not provide information about hollow usage. Indeed, it is often an animal's perception of the quality of the hollow cavity that determines the use of a particular hollow by a particular species. Intraspecific and interspecific differences as well as seasonality within species and sexes play an important role in hollow usage. Thus, aspect, insulating properties, pest infestation, ventilation, shading, proximity to food are among the factors that determine an animal's perception of a desirable hollow. A case study of the Forest Red-tailed Black Cockatoo illustrates the issues involved in integrating these ideas with ecological studies to assess the conservation prognosis of hollow-using fauna.

\section{Case study 3: Logging and hollows: the conservation of the Forest Red-tailed Black Cockatoo}

Abbott (1998) contributed to the debate over appropriate management practices for conserving the hollow-using species of south-western State forest by assessing the hypothesis that a shortage of suitable nest hollows limited the distribution of the Forest Redtailed Black Cockatoo in the region. The results were combined with those of an unpublished study of the abundance of hollows in standing trees in the region and a published inventory of the tree stock. Abbott (1998, p. 182) concluded that

"... both the broad distribution of cockatoos in State forest and the abundance of large trees throughout State forest are inconsistent with the view that commercial utilisation of native forest threatens the Forest Red-tailed Black Cockatoo."

We are unconvinced by this conclusion because the study assessed neither the recruitment rates nor the age structure of this long-lived cockatoo species and so could not tell if populations within State forest are in decline. Instead, we agree with McCarthy et al. (1994, p.83) that "Impacts are best phrased and answered in terms of risk of population decline." Without such data one cannot discount the possibility that the adult Forest Red-tailed Black Cockatoos seen during surveys were breeding at a rate inadequate to replenish the population (as is happening with C. $b$. latirostris, Saunders 1982) and that a crash may be imminent as speculated by Mawson and Long (1994).

We are also concerned that the predicted number of available nest trees given in Abbott (1998) almost certainly overstates the number of suitable nest sites. Some potential nest trees will be located in otherwise unsuitable habitat. Additionally, factors such as fidelity to individual hollows, loss of hollows to competitors such as European Honey Bees Apis melifera, vegetation structure surrounding hollow-bearing trees, and the spatial arrangement of hollow-bearing trees may all render some hollows unsuitable for hollow-nesting fauna (e.g., Lindenmayer et al. 1990; Nelson and Morris 1994; McCarthy et al. 1994; Hershey et al. 1998). Many of these factors are directly related to the scale and spatial distribution of logging coupes, so it is plausible to hypothesise that logging influences the availability of standing nest trees for Forest Red-tailed Black Cockatoo and, thus, the breeding capacity of the species.

Although the above discussion emphasizes the availability of nesting hollows, breeding may also depend on the availability of food. Knowledge of this aspect of the biology of Forest Red-tailed Black Cockatoo is limited. Johnstone and Kirkby (1999) suggested that the extent of flowering and fruiting of the main food trees, jarrah and marri, influences the number of birds that attempt to breed. Therefore, alterations by management, such as by logging on the patterns of flowering and fruiting, as well 
as in the distribution of the tree species, could impact on breeding. Silvicultural strategies, particularly long-term stand management, will increasingly need to account for fauna requirements in intensively managed forest.

Alternative approaches are needed to resolve the question of broad-scale logging impacts on Forest Red-tailed Black Cockatoo throughout State forest. Those used to resolve a similar controversy involving the Spotted Owl Strix occidentalis of North America are appropriate in this case. Noon and McKelvey (1996) reviewed the extensive literature relevant to the Spotted Owl, highlighting the extreme difficulty of conducting meaningful experimental designs to resolve the question of logging impacts on the long-term viability of owl populations. However, they also noted that management plans have properties that can be stated as falsifiable hypotheses and tested with empirical data. Their hypothesis that the population is either stable or increasing is important for testing in selected jarrah forest fauna as well.

We believe that a similar approach is called for in the case of the Forest Red-tailed Black Cockatoo. In particular, there is a critical need for estimates of recruitment rate in populations of long-lived animals to assess the possibility of slow population declines in response to environmental impact. This is consistent with the call of Abbott and Whitford (2002) for ecological studies to support the conclusions of their risk analysis of hollow-using fauna in south-west Western Australia.

\section{Implications derived from studies of hollow nesting fauna}

Assessments of the distribution of a species indicate decline at a broad level as local extinctions occur. They are less informative when assessing the viability of local populations, especially when individuals are long-lived. For example, in an evaluation of the usefulness of surveys to detect population declines in the marine mammal, the Vaquita Phoecena sinus, Taylor and Gerrodette (1993) found that, as population size decreased, so did the likelihood of detecting a decrease, and the minimum detectable rate of decline increased. The ideal solution to this dilemma is to evaluate population sizes and recruitment rates in relation to specific environmental impacts. This has been done for some of the smaller birds of south-western Australia in relation to fire (e.g., Brooker and Brooker 1994 for Splendid Fairy-wrens Malurus splendens in heathland, Russell and Rowley 1998 for Red-winged Fairywrens Malurus elegans in forest including karri). Population viability analysis (PVA) is a particular application of the use of population data, and is one solution to the integration of these data to achieve conservation management outcomes.

\section{Assessing conservation prognoses with PVA}

Proponents of PVA list its advantages (e.g. Lindenmayer and Possingham 1994), many of which address some of the issues highlighted in the previous case study. The process of PVA identifies gaps in information by demanding explicit biological and status information, identifies major threatening processes and highlights trends in population behaviour. PVA also allows the identification of characteristics of a population that have allowed it to persist over extended periods, and enables a quantification of the interacting and potentially cumulative factors that influence population dynamics. PVA also gives a background for integrating research results with onground management activities and enables hypothesis testing for observed fluctuations in population size.

PVA also contributes key information for reserve design such as minimum area requirements. Other management and policy advantages include the ability to compare the relative efficacy of various options, and providing an objective framework for decision-making, target setting for research and management, and planning for species recovery programs (Lindenmayer and Possingham 1994).

In relation to conservation of Australian forest fauna, PVA has been used to effectively model local mammalian extinction and recovery processes (Lunney et al. 2002), population responses of arboreal mammals in relation to modified logging regimes (Lindenmayer and Possingham 1995) and the impact of habitat fragmentation on endangered forest birds (Akcakaya et al. 1995). Lindenmayer et al. (1993) and Lindenmayer and Possingham (1994) have provided reviews of the effectiveness of PVA in Australia.

PVA also has its critics. Abbott and Christensen (1996, p. 209) argue that,

"Moreover, population viability analysis is not testable - it is based on assumptions and does not establish or enable a test of significance to be performed. Overenthusiastic reliance on mathematical models and software, as in population viability analysis, makes it all too easy to avoid thorough scrutiny of assumptions and allows guesswork to masquerade as fact".

However, as Burgman (2000) contends, while PVAs have limitations that compromise their ability to predict the future accurately, so are all predictions error prone. In fact, as Burgman (2000) argues, the lack of completely reliable and verifiable predictions does not detract from the utility of PVAs because their primary output is to reinforce the rigour and transparency of environmental decisionmaking. Burgman (2000) contends that alternative approaches that rest on undefined and unrepeatable subjective processes are likely to produce worse results.

Some of the best features of the use of the PVA approach to assessing a conservation prognosis have been applied in the south-west forests. We provide a case study of population biology and reproductive ecology of two threatened frog species to demonstrate the types of data necessary to link predictions of population viability with conclusions about whether or not particular management activities are impacting on species in jarrah forest ecosystems.

\section{Case study 4: Population biology and repro- ductive ecology of two threatened frogs from south-western Australia}

Conroy (2001) investigated the viability of two threatened frogs from south-western Australia, the White-bellied Frog Geocrinia alba and the Orange-bellied Frog G. vitellina, through detailed metapopulation simulation models. Using extensive life history and spatial data assembled as part of a broader study on the reproductive 
ecology and population biology of these species, Conroy explored the sensitivity of the models, and hence the population dynamics of these species, to changes in both demographic parameters and management regimes. Contrary to the classic amphibian model which suggests that population dynamics are driven by pre-metamorphic (eggs and tadpoles) survival, metapopulation viability was most highly sensitive to juvenile (young frogs) survival, then to fecundity and pre-metamorphic survival, adult survival, and the variability of these survival rates, in that order. Both models were also sensitive to fire frequency, although less consistently so.

Extensive and intensive survey was necessary to provide the data for the PVA and sensitivity analysis. Conroy (2001) estimated demographic parameters for each life stage. Survival during the embryonic and larval phases, clutch size, and development time and were all measured directly by following the fate of large samples of nests in situ during two breeding seasons. Probabalistic markrecapture models were used to estimate survivorship rates for juveniles with data from a three-year mark-recapture study of two cohorts, and for adult males with data from a seven-year mark-recapture study. Survival rates to metamorphosis were consistently high, among the highest observed for anurans, and were similar across the two cohorts studied. By contrast, White-bellied and Orangebellied Frogs have highly variable adult survival rates, among the lowest observed for anurans.
Age at first breeding was measured from individuals marked as metamorphs and recaptured as adults. The juvenile life stage is prolonged, with individual's first breeding at a minimum age of two years. Recruitment and population size fluctuate significantly among years and between populations, even at small spatial scales. Recruitment from the juvenile to the adult life stage is the main driver of population size, with such recruits forming the largest age-class of adults in every year.

Conroy (2001) also examined variation in body size and body condition during the breeding season and related this to chorus tenure and date of recruitment to the breeding chorus. In addition, he examined breeding phenology and within-season variation in clutch size, survival to metamorphosis, weight at metamorphosis, and time to metamorphosis to investigate the factors influencing the timing of reproduction. He found that larger males, and those in better condition, tend to join the chorus earlier and have longer chorus tenures than smaller males or those in poorer condition. Matching this pattern, clutch size (number of eggs) and offspring weight at metamorphosis both decline during the season, while development time to metamorphosis increases during the season. Conroy (2001) hypothesized that the timing of reproduction of larger males may be optimised to take advantage of larger females (and hence larger clutch sizes) early in the season, while that for smaller males to take advantage of the peak of female receptivity late in the season.

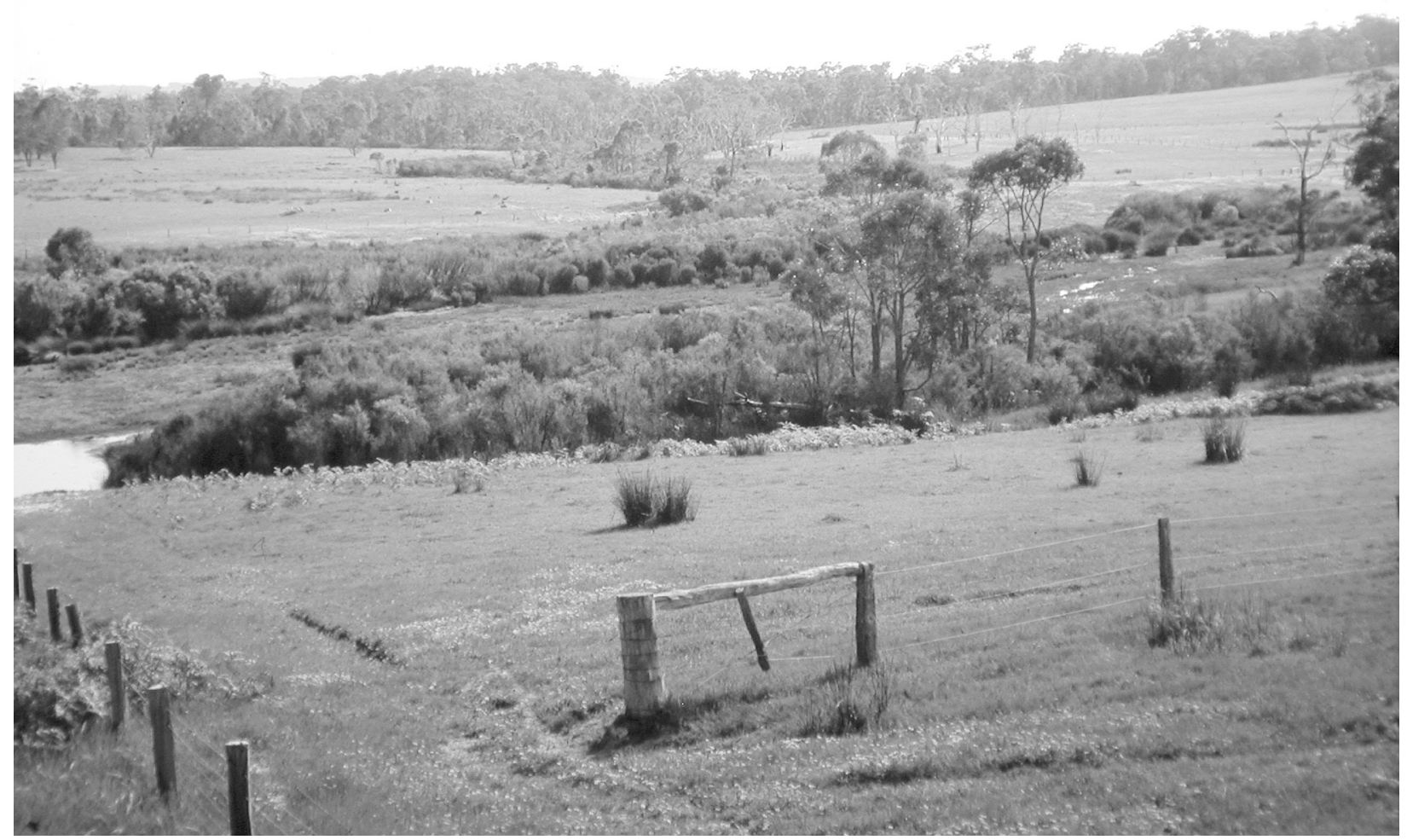

Figure 10. Although extensive land clearing in the range of the White-bellied frog Geocrinia alba limits its susceptibility to catastrophic fires, increased edge effects are likely to impact on small isolated populations of this species. Photo Grant Wardell-johnson. 
Fire represents a major disturbance within the ranges of the Geocrinia rosea group (Driscoll and Roberts 1997, 1998; Conroy 2001). Conroy (2001) re-examined data from the experiments established by Driscoll and Roberts (1997, 1998) and added new data to investigate the impact of fuel reduction burning on populations of the Walpole Frog Geocrinia lutea. He concluded that the spring fuel reduction fires in the experiment had only a small impact on the Walpole Frog population sizes. However, more intensive data collected after fires within the ranges of both the White-bellied and Orange-bellied Frogs indicated that fires have long-term seral effects on populations of these species. These effects include reduced adult body size and body condition, and delayed recruitment and breeding, in years subsequent to the fire. Such effects are likely to persist over several generations given the relationship between delayed reproduction and offspring size.

Wildfire is the most likely catastrophe for the Whitebellied and Orange-bellied Frogs as both species are extremely localised (Wardell-Johnson and Roberts 1993). Conroy (2001) considered the Orange-bellied Frog to be particularly susceptible to fire because of its highly localised distribution in an area of intact forest. Ironically, the extensive land clearing within the range of the Whitebellied Frog probably limits its susceptibility to catastrophic fires. However, increased edge effects are likely to impact on small isolated populations of this species (Figure 10).

The simulation models indicated that the probability of the extinction for these species within the next 100 years is low for the White-bellied Frog, and moderate for the Orange-bellied Frog. However, both species are predicted to have significant range reductions, with relatively few populations persisting over the present century. The genetic differences throughout the current ranges of the White-bellied Frog and the Orange-bellied Frog are very large, particularly over such small spatial scales (Driscoll 1998), so loss of populations will result in a loss of genetic variation for both species (Frankham 1996).

Conroy (2001) suggested that, despite the extensive land clearing within the range of the White-bellied Frog, and the localised distribution of the Orange-bellied Frog, habitat availability is probably not a primary future threat. He was able to argue that habitat manipulation to increase suitability may not be worthwhile for these species because too few populations are above a viable size, and dispersal is unlikely. Rather, he suggested that the management of several core populations for these species may be more beneficial than spreading resources thinly. This was despite Driscoll's (1998) finding of high levels of genetic variation between populations of these species.

The recent (2000) acquisition of a 1570 ha block of private land, $20 \mathrm{~km}$ south-east of Margaret River, provides statutory protection for the core habitat of this species. Because statutory protection provides no guarantee for long-term viability, an effective and long-term monitoring program has been established for these species informed by reliable species demographic data. This will alert the management agency (Department of Conservation and Land Management, DCLM) of changes in population trends in a range of sites, which will if necessary, provide the best opportunity for effective management intervention.

\section{Implications of the population case studies}

Case studies three and four developed our view that the determination of recruitment and trends in the population are essential for an assessment of risk. Risk analysis, when critical aspects of the biology of participating species are weakly known, may lead to misclassification of species. While excellent work has been done on hollow formation and abundance, critical population studies of hollow-users to allow the appreciation of likely risk and appropriate management actions are lacking in south-western Australia. Assessments of recruitment and population trends are more sensitive instruments than surveys in determining impacts and providing early warning of declines. We contend that a focus on demography, especially recruitment, is far more important to management than species specific (rather than biogeographic) surveys alone because it highlights threatening processes before their impacts are irremediable (although see Lunney et al. 2000). This allows for the effective implementation of monitoring programs for detecting change. Hence, population changes can be understood and remedial action taken.

Critical hypothesis testing is now required in Western Australian forests. The larger hollow-using birds and the arboreal mammals are excellent subjects for study. Short-term impact studies, such as the study of the Forest Red-tailed Black Cockatoo reviewed here, cannot take into account successful breeding and recruitment, which are essential for long-term population persistence. Testing of predictive hypotheses regarding population trends and habitat availability for ground-dwelling fauna are equally important as those that we propose for hollowusers. Approaches to the study of hollow occupancy and use in Australia in general, and south-western Australia in particular, must expand and become more holistic to understand the needs of hollow-dependent fauna. Research must not only include hollow development and availability in trees but also usage, competition and seasonality by different hollow-dependent species, components that are invariably determined by the quality of the hollow cavities (e.g. size, position, temperature and humidity - see Frank and Dietz 1999).

\section{Integrated landscape and population studies}

Localized actions repeated across a landscape have implications at both landscape and individual population scales can affect adaptive management (Lindenmayer and Franklin 2002). As a broad scale activity causing environmental changes in the jarrah forest, logging is an excellent case study to link population and landscapescale research.

\section{Logging in jarrah forest}

Logging of open-forest dominated by jarrah began soon after European settlement and by 1831 jarrah had become the Western Australian colony's first export (Stoate 1947). Most jarrah forest has at some stage been logged in the ensuing 170 years (Havel 1989; Mills 1989). The 
development of a timber industry can be grouped into three periods, beginning with unimpeded exploitation, increasing in intensity between 1880 and the promulgation of the Forests Act in 1918, the expansion of State forest, silvicultural reconstruction, fire exclusion and emphasis on timber production and water catchment protection until the early 1960s. The third and contemporary phase of multiple-use values in management included the replacement of fire exclusion with prescribed burning and intensive utilization of forest products via woodchipping (the latter in forest dominated by karri - Carron 1985; Burrows et al. 1995; Dargavel 1995; Calver and WardellJohnson 2003).

Logging and silvicultural operations have varied greatly over decades in jarrah forest (Jarvis 1981; Havel 1989; Mills 1989; Stoneman et al. 1989; Heberle 1997), with silvicultural operations now taking into account previous history and the present levels of advanced growth more fully than in the past. However, while current logging operations in forest including jarrah now include areas of gaps and retained patches, the latter are removed in a later cutting cycle. In addition, there are markets for a wider range of size-classes and timber qualities for jarrah and marri than before, which encourages intensive logging (see Norwood et al. 1995 for a description of gaps in jarrah forest). Despite the broadscale nature of the timber industry and the controversy of logging and logging impacts, few reliable data were available on the impacts of logging on the fauna of jarrah forest communites until well into the 1990s. Thus few studies of logging impacts on fauna in Western Australia had been completed and little of that work was experimental (Calver et al. 1998, Calver and Dell 1998). This prevented the effective integration of landscape and population studies to allow adaptive management in the face of broadscale management regimes (Wardell-Johnson and Nichols 1991).

\section{Case study 5: Lessons from the Kingston study}

To redress the deficiency in the state of knowledge concerning the impacts of logging in the jarrah forest, a detailed experimental study was implemented in jarrah forest $25 \mathrm{kms}$ north-east of Manjimup (Burrows et al. 1993). It came to be known as the Kingston study, after one of the three forest blocks involved. Forest blocks are local forest management areas averaging around 5000 ha in extent, the others used for the study being Warrup and Winejup. The total area is approximately 15000 ha and a summary of site characteristics is given by Morris et al. (2000). The overall experimental design followed BACI (before - after - control - impact) principles, with sampling before and after the logging and a balance of control and impact sites. Approximately a year before the first sampling, foxes were baited using dried meat impregnated with 1080 toxin across the study area to reduce predation and thus encourage increases in numbers of native mammals to the point where logging impacts could be determined (Morris et al. 2000). The logging regime was a mix of areas where $95 \%$ of the basal area was removed, with retention of 3 habitat trees per hectare (gap creation), and areas which had around $80 \%$ basal area removed (shelterwood). Each regime had unlogged adjacent areas as internal controls and unlogged areas up to $1 \mathrm{~km}$ away as external controls (Craig 1999, Morris et al. 2000). Post-logging burns occurred approximately 12 months after logging (Morris et al. 2000). Integrated studies aimed to assess the impact of logging on mammals (Morris et al. 2000, 2003), birds (Craig 1999) and terrestrial invertebrates (Strehlow et al. 2002) were conducted. Burrows et al. (2001) give a concise synthesis of the findings, including data on some mammals not covered in Morris et al. (2000) - see also Wayne et al. (2000, 2001) for background data on the possum species. Rhind (1996, 1998) also assessed logging impacts on mammals in a nearby area at approximately the same time as the Kingston study, so her results are reviewed along with those from the main experiment.

The total abundance and species richness in the terrestrial invertebrate community was unchanged by logging. Short-term impacts on Blattodea, Coleoptera, Diptera, Hemiptera and Orthoptera were redressed quickly and invertebrate communities on control sites resembled those on impact sites after 10 months. Indeed, seasonal and between year climate fluctuations affected invertebrate populations more than the logging activity (Strehlow et al. 2002). Although these results did not include the post-logging burn, changes in the invertebrate fauna after the post-logging burn were transitory, suggesting that the groups studied are resilient to fire used in this way (Abbott et al. 2002).

Six bird species (Golden Whistler Pachycephala pectoralis, Western Gerygone Gerygone fusca, White-naped Honeyeater Melithreptus lunatus, Spotted Pardalote Pardalotus punctatus, Striated Pardalote Pardalotus striatus, and Grey Fantail Rhipidura fuliginosa) all declined in gap and shelterwood areas following logging but before the postlogging burn. The first five of these species glean invertebrates in the canopy and sub-canopy, so logging would reduce foraging sites and food supply. The Grey Fantail hawks from low foliage and may have lost perching sites. Three gleaners increased in abundance by using piles of logging slash as a foraging site (Splendid Fairywren, Red-winged Fairy-wren, White-browed Scrubwren Sericornis frontalis), but this opportunity would disappear after the postlogging burn. Dusky Woodswallows Artamus cyanopterus also increased, presumably because the opening of the canopy improved opportunities for hawking (Craig 1999).

Significant numbers of Common Brushtail Possums were killed during logging in gap (33 - $35 \%$ ) and shelterwood (67 \%) (Morris et al. 2000), However, retained habitat trees appeared to encourage persistence of Common Brushtail Possums (Morris et al. 2000). Burrows et al. (2001) noted an overall 30-35 \% decline in Common Brushtail Possums in logged areas and more severe impacts on Western Ringtail Possums. Twelve of the 17 radio-collared Western Ringtail Possums from logged areas died within three weeks of logging and all animals were dead within 20 months of logging. The 12 radiocollared animals on control sites lived longer, but were all dead within 40 months of logging, reflecting an '... overall decline at the landscape scale' (Burrows et al. 2001, p. 17, Wayne et al. 2000, 2001 also give data on changes 
in abundance of Western Ringtail Possum). Impacts on two ground-dwelling mammals, the Woylie and the Southern Brown Bandicoot Isoodon obesulus, were minor, while results for the Chuditch were ambivalent because of artefacts of sampling (Morris et al. 2000, Burrows et al. 2001, Morris et al. 2003). At a nearby site, Rhind (1996) reported $17 \%$ possum mortality overall, using combined data for Common Brushtail Possums and the Western Ringtail Possum. Brush-tailed Phascogale continued to travel through and forage in logged areas, indicating high fidelity to territories despite logging (Rhind 1998). However, Rhind (1996, 1998) noted that Brush-tailed Phascogales rarely nested in retained habitat trees, retreating to unlogged forest. Thus a concentration on the retention of habitat trees does not necessarily retain the full range of arboreal fauna.

The long-term persistence of mammals and birds is likely to be related to subsequent logging practices. Craig (1999) added that the bird species that declined after logging could be lost at the coupe level if unlogged buffers were cut within 20 - 30 years time as planned. He therefore recommended leaving unlogged buffers for 120 - 190 years until regrowth matured. Rhind (1998) was also concerned over the long-term persistence of Brush-tailed Phascogales following logging of buffers and logging is listed as a possible management concern for this species in Environment Australia's current Marsupial and Monotreme Action Plan (Maxwell et al. 1996). Morris et al. (2000) made no such qualification, highlighting that Common Brushtail Possums, Southern Brown Bandicoots, Woylies and Chuditch all persisted in the study area in the short-term after logging and burning. We hope that Morris et al. (2000) are right, but until further data are available we concur with Craig (1999) and Rhind (1998) because their interpretations are long-term and err on the side of caution.

The impacts of logging disturbances were interactive with predation by foxes. Although Morris et al. (2000) reported large reductions in Red Fox activity in baited versus unbaited areas, they nevertheless noted predation by foxes and a tendency for migrant foxes to replace those killed. Burrows et al. (2001) blamed increased predation by foxes and feral cats and reduced recruitment following logging for declines in Western Ringtail Possum numbers. The observation of cat predation is significant. Risbey et al. (2000) have demonstrated that feral cat impacts on small mammal numbers in semi-arid Australia were exacerbated when foxes were controlled. Such responses may also be occurring in the forest region. Rhind (1998) reported increased Red Fox activity and predation of Brush-tailed Phascogales in poor condition following logging in a baited area.

\section{Implications}

Two important issues emerge from these findings. The first is that the retention of unlogged buffer zones in logged coupes is critical to the persistence of a range of birds and mammals, possibly more so than retaining habitat trees. At the least, logging in any of these areas in jarrah forest within the 120 year time frame suggested by Craig (1999) should be treated as an experiment with appropriate controls to assess his predictions and those of Rhind (1998) concerning the persistence of fauna. Furthermore, fox baiting also appears critical and there is clear endorsement for its continuation on a long-term basis over as wide a geographic range as possible. Without baiting, very high levels of predation are likely to follow logging. In view of the observations of predation by feral cats reported by Burrows et al. (2001), the possibility of increases in cat numbers following control of foxes should also be investigated. Predation by the Red Fox appears interactive with the disturbance caused by logging, causing deaths despite preventive baiting (Rhind 1998, Morris et al. 2000). However, the situation would be much worse without baiting, so Red Fox control remains an essential management tool. In fact, control of foxes in south-western forest ecosystems has been a major factor in the recovery, and hence change in conservation status, of several species of vulnerable mammal (Morris et al. 2003).

The second issue concerns the statistical power of experimental studies, which often impeded the detection of significant impacts. It was not a major issue for Strehlow et al. (2002), presumably because of the level of sampling intensity possible in their study of logging impacts on terrestrial invertebrates. However, Craig (1999) found that inadequate power prevented confident assessment of logging impacts on many bird species, an issue also discussed by Williams et al. (2001) with regard to experimental studies in karri forest. Although Morris et al. (2002) and Rhind (1996, 1998) did not discuss power, the sampling problems associated with mammal studies suggest that is likely to be a factor in their conclusions as well. Appendix 3 of Burrows et al. (2001) acknowledges problems with power in determining logging impacts on the Western Ringtail Possum. With hindsight, the greatest limitation with respect to the Kingston study may thus be a result of the limited replication provided, and hence limited power of the experiment to allow effective guidelines to be provided to management. Given this experience, we believe that when resources are limited it is more useful to concentrate on fewer taxa to achieve greater replication than provide comprehensive taxon-based assessment with limited replication. The situation of the limited effectiveness of low power applies to both experimental research and to monitoring programs. It is particularly important in monitoring programs that are designed to detect change, and hence allow a modification of management behaviour (see Wardell-Johnson and Calver 2002).

The difficulties with power reported by some authors may be grounds for using an interval estimation technique rather than hypothesis testing to report the results of impact experiments. Conventional hypothesis testing presents a significance test of the null hypothesis that $\mu_{1}-\mu_{2}=0$, whereas interval estimation presents a confidence interval for $\mu_{1}-\mu_{2}$ (Steiger and Fouladi 1997). Thus interval estimation avoids the influence of sample size, sample variance, the number of comparisons performed and the conventional selection of a Type I error level on the conclusion of a significance test. Instead, it highlights the range of possible effects that could occur under the experimental conditions and presents the maximum information to decision-makers. For example, a conventional significance test may fail to reject a null hypothesis of no impact. However, the $90 \%$ confidence interval for the difference between the means may range 
up to a $40 \%$ difference, a possible outcome likely to be of concern to managers. Suter (1996) discusses the implications of hypothesis testing and interval estimation for ecological risk assessment, concluding that the hypothesis testing approach may often be inappropriate.

Ultimately, silvicultural measures to ensure the persistence of all hollow-using fauna in the jarrah forest may or may not be successful. While they are undeniably of value, whether they are sufficient can only be judged by assessments of the critical variables of population trends and reproductive success (McCarthy et al. 1994). This is especially important in long-lived species, where surveys such as that used by Abbott (1998) are problematic because declines may be slow to appear (Mawson and Long 1994).

\section{Conclusion}

Despite 170 years of jarrah forest logging at a level identified as unsustainable by Calver and Wardell-Johnson (2003), plus a growing recognition of interactions between impacts in the jarrah forest, there remains a critical lack of reliable, site-based and species demographic data upon which to base effective adaptive management in the context of broad scale extractive industries such as logging and mining for bauxite. While we provide cautious support for the concept that production forest can contribute to biodiversity conservation (e.g. Lindenmayer and Franklin
2002), we also concur with Norton and Kirkpatrick (1995) that there is an urgency to make this a reality. In Western Australia, the critical questions of recruitment and population trends remain essentially unassessed, a troubling omission if one agrees with McCarthy et al. (1994) that conservation issues are best stated in terms of risk of population decline.

Overall, the review indicates that site-based studies highlighting biogeographic patterns, and critical factors of population decline in key indicator species are the most serious deficits in current understanding. Without them, the adequacy of environmental safeguards on current land-use remains uncertain. For the management of southwestern Australian forests, there is a clear requirement for an information-rich and integrative environment that is appropriate for subdued but heterogeneous environments to allow scientific and public confidence that the forests are being managed in the light of the most effective information. We perceive a need for a combination of taxon specific studies, the modelling of biological patterns from an ecosystem perspective, and studies involving the interactions of disturbance regimes in the face of increasing rates of global and local change affecting disturbance. These will be required to effectively portray and manage at a scale appropriate for diverse ecological systems in the flat landscapes of the jarrah forests of Western Australia.

\section{Acknowledgements}

We thank Monika Rhodes for insight on the behaviour of hollow requiring species and for German translation.
The paper was improved greatly by the comments of two reviewers and editorial guidance from Dan Lunney.

\section{References}

Anonymous, 1970. Controlled burning for forest conservation. Forest Focus 3: 3-8.

Abbott, I., 1998. Conservation of the forest Red-tailed Black Cockatoo, a hollow-dependent species, in the eucalypt forests of Western Australia. Forest Ecology and Management 109: 175-185.

Abbott, I., 2001. The Bilby Macrostis lagotis (Marupialia: Peramelidae) in south-western Australia: original range limits, subsequent decline, and presumed regional extinction. Records of the Western Australian Museum 20: 271-305.

Abbott, I., 2003. Aboriginal fire regimes in south-west Western Australia: evidence from historical documents. Pp 119-146 in Fire in ecosystems of south-west Western Australia: impacts and management, edited by I. Abbott and N. Burrows, Backhuys Publishers, Leiden, The Netherlands.

Abbott, I. and Burrows, N., 1999. Biodiversity conservation in the forests and associated vegetation types of southwest Australia. Australian Forestry 62: 27-32.

Abbott, I., Burbidge, T., Strehlow, K., Mellican, A. and Wills, A., 2002. Logging and burning impacts on cockroaches, crickets and grasshoppers, and spiders in jarrah forest, Western Australia. Forest Ecology and Management. 174: 383-399.

Abbott, I. and Christensen, P., 1994. Application of ecological and evolutionary principles to forest management in Western Australia. Australian Forestry 57: 109-122.

Abbott, I. and Christensen, P., 1996. Objective knowledge, ideology and the forests of Western Australia. Australian Forestry 59: 206-212.
Abbott, I. and Loneragan, O., 1986. Ecology of Jarrah (Eucalyptus marginata) in the northern Jarrah forest of Western Australia. Department of Conservation and Land Management, Perth, Western Australia.

Abbott, I. and Whitford, K. R., 2002. Conservation of vertebrate fauna using hollows in forests of south-west Western Australia: strategic risk assessment in relation to ecology, policy, planning, and operations management. Pacific Conservation Biology 7: 240-255.

Akcakaya, H.R., McCarthy M.A., and Pearce J.L., 1995. Linking landscape data with population viability analysis management options for the helmeted honeyeater Lichenostomus melanops cassidix. Biological Conservation 73:169-176.

Armstrong, J. A. and Abbott, I., 1995. Sustainable conservation - a practical approach to conserving biodiversity in Western Australia. Pp. 21-28 in Conservation through sustainable use of wildlife, edited by G. C. Grigg, P. T. Hale and D. Lunney, Centre for Conservation Biology, the University of Queensland, Brisbane, Queensland.

Bond, W. J. and van Wilgen, B.W., 1996. Fire and Plants. Chapman \& Hall, London. United Kingdom.

Brooker, L. C., Brooker, M. G., 1994. A model for the effects of fire and fragmentation on the viability of the Splendid Fairywren. Pacific Conservation Biology 1: 344-358.

Buchanan, A.P. and Wardell-Johnson, G., 1994. Managing animal habitat using remote sensing and geographic information systems. Pp 1022-1031 in Proceedings of the Fifth Australasian remote sensing conference, Perth, Western Australia. 
Burbidge, A. A., and McKenzie, N. L. 1989. Patterns in the modern decline of Western Australia's vertebrate fauna: causes and conservation implications Biological Conservation 50: 143-198.

Burgmann, M., 2000. Population viability analysis for bird conservation: prediction, heuristics, monitoring and psychology. Ети 100: 347-353.

Burrows, N. and Wardell-Johnson, G. W., 2003. Fire and plant interactions in forested ecosystems of south-west Australia: a review Pp. 225-268 in Fire in ecosystems of south-west Western Australia: impacts and management, edited by I. Abbott and N. Burrows, Backhuys Publishers, Leiden, The Netherlands.

Burrows, N. D., Ward, B. and Cranfield, R., 2002. Short-term impacts of logging on understorey vegetation in a Jarrah forest. Australian Forestry 65: 47-58.

Burrows, N., Friend, G., Morris, K., Stoneman, G., WardellJohnson, G. and Williams, M., 1993. A proposed integrated study of the effects of timber harvesting on the Jarrah forest ecosystem, Department of Conservation and Land Management, Perth, Western Australia.

Burrows, N.D., Ward, B. and Robinson, A. D., 1995. Jarrah forest fire history from stem analysis and anthropological evidence. Australian Forestry 58: 7-16.

Busby, J. R., Davies, S. J. J. F., 1977. Distribution of Birds on the Australian Mainland: Dr D.L. Serventy's Maps. CSIRO Publications, Australia.

Calver, M. C. and Wardell-Johnson, G., 2004. Sustained unsustainability? An evaluation of the history of logging in the jarrah forests of Western Australia and its consequences for fauna conservation. Pp. 94-114 in Conserving Australia's forest fauna, (2 ${ }^{\text {nd }}$ edition), Royal Zoological Society of New South Wales, Mosman, NSW

Calver, M. C. and Dell, J., 1998. Conservation status of mammals and birds in south-western Australian forests. I. Is there evidence of direct links between forestry practices and species decline and extinction? Pacific Conservation Biology 4: 296-314.

Calver, M. C., Dickman, C. R., Feller, M. C., Hobbs, R. J., Horwitz, P., Recher, H. F. and Wardell-Johnson, G., 1998. Towards resolving conflict between forestry and conservation in Western Australia. Australian Forestry 61: 258-266.

Calver, M. C., Hobbs, R. J., Horwitz, P. and Main, A. R., 1996. Science, principles and forest management: a response to Abbott and Christensen. Australian Forestry 59: 1-6.

Carron, L. T., 1985. A history of forestry in Australia. Australian National University Press, Canberra, Australia.

Chase, A. and Sutton, P., 1981. Hunter-gatherers in a rich environment: aboriginal coastal exploitation in Cape York Peninsula. Pp 1819-1852 in Ecological Biogeography of Australia, edited by A. Keast, Dr W. Junk, The Hague.

Christensen, P. E. S., 1980. The biology of Bettongia penicillata (Gray, 1937), and Macropus engenii (Desmarest, 1817) in relation to fire. Bulletin 91, Forests Department of Western Australia, Perth.

Christensen, P. 1997a. A review of the knowledge of the effects of key disturbances on fauna in the south-west forest region, Unpublished report to the Commonwealth and Western Australian Governments for the Western Australian Regional Forest Agreement.

Christensen, P. 1997b. Fauna conservation in production forests in Western Australia. Pp. 466-470 in Conservation outside nature reserves, edited by P. Hale and D. Lamb, Centre for Conservation Biology, The University of Queensland, Brisbane, Australia.
Christensen, P. and Abbott, I., 1989. Impact of fire in the eucalypt forest ecosystem of southern Western Australia: a critical review. Australian Forestry 52: 103-121.

Christensen, P. E. S., 1992. The Karri forest. Department of Conservation and Land Managment, Perth, Western Australia.

Christensen, P. and Annells, A., 1985. Fire in southern tall forests. Pp. 67-82 in Fire Ecology and Management in Western Australian Ecosystems, edited by J. Ford, WAIT Environmental Studies Group Report No. 14.

Christensen, P. E. S., Liddelow, G. and Hearn, R., 2001. Fauna assessment in timber harvesting coupes in western Australia. Unpublished report. Department of Conservation and Land Management, WA

Christensen, P. E. S., Maisey, K. and Perry, D. H., 1984. Radio-tracking the Numbat, Myrmecobius fasciatus, in the Perup forest of Western Australia. Australian Wildlife Research 11: 275-288.

Churchward, H. M., MacArthur, W. M., Sewell, P. L. and Bartle, G. A., 1988. Landforms and soils of the south coast and hinterland, W.A., Northcliffe to Manypeaks. CSIRO Division of Water Resources Div. Rep. 88/1, Canberra, 153 pp.

Conacher, A., 1983. Environmental management implications of intensive forestry practices in an indigenous forest ecosystem: a case study from south-western Australia. Pp. 117-151 in Progress in resource management and environmental planning, edited by $\mathrm{T}$. O'Riordan and K. V. Turner, John Wiley \& Sons, New York.

Conroy, S. D. S., 2001. Population biology and reproductive ecology of Geocrinia alba and G. vitellina, two threatened frogs from south-western Australia. PhD Thesis, University of Western Australia.

Craig, M. D. 1999. The short-tem impacts of timber harvesting on the Jarrah forest avifauna. Perth, Western Australia, PhD Thesis, University of Western Australia.

Dargavel, J. 1995. Fashioning Australia's Forests. Oxford University Press, Oxford, United Kingdom.

Davey, S. M., Norton, T. W., 1990. State forests in Australia and their role in wildlife conservation. Proceedings of the Ecological Society of Australia 16: 323-345.

Dell, B., Havel, J. J. and Malajczuk, N., Eds. 1989. The jarrah forest: a complex mediterranean ecosystem. Kluwer Academic Publishers, Dordrecht, The Netherlands.

Driscoll, D. A. 1998. Genetic structure, metapopulation processes and evolution influence the conservation strategies for two endangered frog species. Biological Conservation 83: 43-54.

Driscoll, D. A. and Roberts, J. D., 1997. Impact of fuelreduction burning on the frog Geocrinia lutea in southwest Western Australia. Australian Journal of Ecology 22: 334-339.

Driscoll, D. A. and Roberts, J. D., 1998. Corrigenda. Australian Journal of Ecology 23: 598.

Ellis, M. and Jones, B., 1992. Observations of captive and wild Western Ringtail Possums Pseudocheirus occidentalis. The Western Australian Naturalist 19: 1-10.

Faunt, K., 1992. Formation, frequency and longevity of hollows in Jarrah: Interim report, Department of Conservation and Land Management, Western Australia.

Frankham, R., 1996. Relationship of genetic variation to population size in wildlife. Conservation Biology 10:1500-1508

Frank, R and Dietz, M., 1999. Fledermäuse im Lebensraum Wald. Merkblatt 37, Hessisches Ministerium für Umwelt, Landwirtschaft und Forsten, Germany, pp 53-98 (Bats in the forest habitat, report series 37, Department of Environment, Agriculture and Forestry, Hessen, Germany.) 
Gardner, R. H., Hargrove, W.W. Turner, M.G. and Romme, W.H., 1996. Climate change, disturbances and landscape dynamics. Pp 149-172 in Global Change and Terrestrial Ecosystems, edited by B. H. Walker and W. L. Steffan, IGBP Book Series No 2, Cambridge University Press, Cambridge, United Kingdom.

Garkakalis, M.J., Calver, M.C., Wilson, B.A. and Hardy, G.E.St.J. 2004 Habitat alteration caused by introduced plant disease: a significant threat to the conservation of Australian forest fauna. Pp. 899-913 in Conservation of Australia's forest fauna 2nd edition, edited by D. Lunney, Royal Zoological Society of New South Wales, Mosman, NSW, Australia.

Gibbons, P. G. and Lindenmayer, D. B., 2002. Hollows and wildlife conservation in Australia. CSIRO Publishing, Melbourne, Australia.

Gibson, N., Keighery, B. J. Keighery, G. J., Burbidge, A. H. and Lyons, M. N., 1994. A floristic survey of the southern Swan Coastal Plain. Unpublished report for the Australian Heritage Commission prepared by the Department of Conservation and Land Management and the Conservation Council of Western Australia (Inc.)

Gill, A. M., 1981. Adaptive responses of Australian vascular plant species to fire. Pp 243-272 in Fire and the Australian Biota, edited by A. M. Gill, R.H. Groves and I. Noble. Australian Academy of Science, Canberra.

Gioia, P. and Pigott, J. P., 2000. Biodiversity assessment: a case study in predicting richness from the potential distributions of plant species in the forests of south-western Australia. Journal of Biogeography 27: 1065-1078.

Hallam, S. J., 1975. Fire and hearth: a study of Aboriginal usage and European usurpation in south-western Australia. Australian Institute of Aboriginal Studies, Canberra.

Harris, A. C. and Wallace, W. R., 1959. Controlled burning in Western Australian forest practice. Forests Department of Western Australia, Perth, Western Australia.

Havel, J. J., 1989. Land use conflicts and the emergence of multiple land use. Pp. 281-314 in The Jarrah Forest edited by B. Dell, J. J. Havel and N. Malajczuk, Kluwer Academic Publishers, Dordrecht, The Netherlands.

Havel, J. J., 2000. Ecology of the forests of south-western Australia in relation to climate and landforms. $\mathrm{PhD}$. Thesis, Murdoch University, Western Australia.

Havel, J. J. and Mattiske, E. M., 2000. Vegetation mapping of south-west forest regions of Western Australia (6 maps). Reprint to CALMScience for the Regional Forest Agreement. Perth, Western Australia, Department of Conservation and Land Management.

Heberle, G., 1997. Timber harvesting of Crown land in the south-west of Western Australia: an historical review with maps. CALM Science 2: 203-224.

Hershey, K. T., Meslow, E. W., Ramsey, F. L., 1998. Characteristics of forests at spotted owl nest sites in the Pacific northwest. Journal of Wildlife Management 62: 1398-1410.

Hopper, S. D. and Wardell-Johnson, G., in press. Eucalyptus virginea and E. relictua (Myrtaceae), two new rare forest trees from south-western Australia allied to E. lanepoolei, and a new phantom hybrid. Nuytsia

Hopper, S. D., Keighery, G. J and Wardell-Johnson, G., 1992. Flora of the karri forest and other communities in the Warren Subdistrict of Western Australia. In: Research on the Impact of Forest Management in South-west Western Australia, Occasional Paper 2/92. Department of Conservation and Land Management, pp 1-32.
Horwitz, P., Pemberton, M. and Ryder, D., 1999. Catastrophic loss of organic carbon from a management fire in a peatland in south-western Australia. Pp. 487-501In: Wetlands for the Future, edited by A. J. McComb and J. A., Gleneagles Press, Adelaide.

Horwitz, P., Judd, S. and Sommer, B., 2003. Fire and organic substrates: soil structure, water quality and biodiversity in far south-west Western Australia. Pp. 225-268 in Fire in ecosystems of south-west Western Australia: impacts and management, edited by I. Abbott and N. Burrows, Backhuys Publishers, Leiden, The Netherlands.

How, R. A. and Hillcox, S. J., 2000. Brushtail possum, Trichosurus vulpecula, populations in south-western Australia: demography, diet and conservation status. Wildlife Research 27: 81-89.

Hughes, L. 2003. Climate change and Australia: trends, projections and impacts. Austral Ecology 28: 423-443.

Hynes, R. A. and Chase, A. K., 1982. Plants, sites and dormiculture: Aboriginal influence upon plant communities in Cape York Peninsula. Archaeology in Oceania 17: 38-50.

Inions, G. B., Tanton, M. T. and Davey, S. M., 1989. Effects of fire on the availability of hollows in trees used by the Common Brushtail Possum, Trichosurus vulpecula Kerr, 1792, and the Ringtail Possum, Pseudocheirus peregrinus Boddaerts, 1785. Australian Wildlife Research 16: 449-458.

Jarvis, N. T., 1981. Western Australia: an atlas of human endeavour, 1829-1979. Education and Lands and Surveys Departments of Western Australia, Perth, Western Australia.

Johnstone, M. H., Lowry, D.C. and Quilty, P. G., 1973. The geology of southwestern Australia- a review. Journal of the Royal Society of Western Australia 56: 5-15.

Johnstone, R. E., Kirkby, T., 1999. Food of the forest redtailed Black Cockatoo Calyptorynchus banksii naso in southwest Western Australia. The Western Australian Naturalist 22: 167-178.

Jones, B. A., How, R. A. and Kitchener, D. J., 1994. A field study of Pseudocheirus occidentalis (Marsupialia: Petauridae). I. Distribution and habitat. Wildlife Research 21: 175-187.

Jones, B. A., How, R. A. and Kitchener, D. J., 1994. A field study of Pseudocheirus occidentalis (Marsupialia: Petauridae). II. Population studies. Wildlife Research 21: 189-201.

Jones, B. and Hillcox, S., 1995. A survey of the possums Trichosurus vulpecula and Pseudocheirus occidentalis and their habitats in forest at Ludlow, Western Australia. The West Australian Naturalist 20: 139-150.

Kinnear, J. E., Sumner, N. R. and Onus, M. L., 2002. The red fox in Australia - an exotic predator turned biocontrol agent. Biological Conservation 108: 335-359.

Kinnear, J. E., Onus, M. L. and Sumner, N. R., 1998. Fox control and rock-wallaby population dynamics - II. An update. Wildlife Research 25: 81-88.

Kinnear, J. E., Sumner, N. R. and Onus, M. L., 2002. The red fox in Australia - an exotic predator turned biocontrol agent. Biological Conservation 108: 335-359.

Kleining, G. and Witt, H., 2001. Discovery as Basic Methodology of Qualitative and Quantitative Research. Forum: Qualitative Social Research. Accessed Feb 2001: http:// qualitative-research.net/fqs-texte/1-01/1-p1kleiningwitt-e.html.

Lambeck, R. 1997. Focal species: a multi-species umbrella for nature conservation. Conservation Biology 11: 849-856 
Lamont, B. B., Ward, D. J., Eldridge, J., Korczynski., Colangelo, W. I., Fordham, C., Clements, E. and Wittkuhn, R., 2003. Believing the Balga; A new method for gauging the fire history of vegetation using grasstrees. Pp 147-170 in Fire in ecosystems of south-west Western Australia: impacts and management, edited by I. Abbott and N. Burrows, Backhuys Publishers, Leiden, The Netherlands.

Lindenmayer, D. B. and Franklin, J. F., 2002. Conserving forest biodiversity: a comprehensive multiscaled approach. Island Press, Washington, DC.

Lindenmayer, D. B. and Possingham, H. P., 1995. The conservation of arboreal marsupials in the montane ash forests of the central highlands of Victoria, south-eastern Australia - VII. Modelling the persistence of Leadbeater's Possum in response to modified timber harvesting practices. Biological Conservation 73: 239-257.

Lindenmayer, D. B., Clark, T. W., Lacy, R. C. and Thomas, V. C., 1993. Population viability analysis as a tool in wildlife conservation policy: With reference to Australia. Environmental Management 17: 745-758.

Lindenmayer, D. B., Cunningham, R. B., Nix, H. A., Tanton, M. T., Smith, A. P., 1991. Predicting the abundance of hollowbearing trees in montane ash forests of south-eastern Australia. Australian Journal of Ecology 16: 91-98.

Lindenmayer, D. B., Margules, C. R. and Botkin, D., 2000. Indicators of forest sustainability biodiversity: the selection of forest indicator species. Conservation Biology 14: 941-950.

Lindenmayer, D. P. and Possingham, H. P., 1994. The risk of extinction: ranking management options for Leadbeater's Possum using population viability analysis. Centre for Resource and Environmental Studies, Australian National University, Canberra.

Lunney, D., Curtin, A. L., Ayers, D., Cogger, H. G., Dickman, C. R., Maitz, W., Law, B. and Fisher, D. 2000. The threatened and non-threatened native vertebrate fauna of New South Wales: status and ecological attributes. Environmental and Heritage Monograph Series No. 4. Pp 1-132. National Parks and Wildlife Service, Hurstville, NSW.

Lunney, D., O’Neill, L., Matthews, A. and Sherwin, W. B. 2002. - Modelling mammalian extinction and forecasting recovery: koalas at Iluka (NSW, Australia). Biological Conservation 106:101-113.

Mattiske, E.M. and Havel, J.J., 1998. Regional Forest Agreement, vegetation complexes - Perth, Pinjarra, Collie, Busselton/Augusta, Pemberton, Mount Barker- Western Australia. 1:250 000 maps. Department of Conservation and Land Management WA, Perth and the Department of Environment and Heritage, Canberra, ACT.

Mawson, P. R. and Long, J. L., 1994. Size and age parameters of nest trees used by four species of parrot and one species of cockatoo in South-west Australia. Emu 94: 149-155.

Mawson, P. R. and Long, J. L., 1997. Size and age of nest trees: A reply to Stoneman, Rayner and Bradshaw (1997). Emu 97: 181-182.

Maxwell, S., Burbidge, A. A. and Morris, K., 1996. The 1996 action plan for Australian marsupials and monotremes. Wildlife Australia, Canberra, Australian Capital Territory, Australia.

McCarthy, M. A., Pearce, J. L. and Burgman, M. A., 1994. Use and abuse of wildlife models for determining habitat requirements of forest fauna. Australian Forestry 57: 82-85.

McCaw, W. L. and Burrows, N. D., 1989. Fire management. Pp. 317-334 in The jarrah forest: a complex Mediterranean ecosystem, edited by B. Dell, J. J. Havel and N. Malajczuk, Kluwer Academic Publishers, Dordrecht, The Netherlands.
McCaw, W. L. and Hanstrum, B., 2003. Fire environment of Mediterranean south-west Western Australia. Pp. 87-106 in Fire in ecosystems of south-west Western Australia: impacts and managment, edited by I. Abbott and N. Burrows, Backhuys Publishers, Leiden, The Netherlands.

McComb, W., 1994. Mapping potential habitat for vertebrates in forests of Western Australia. Final report. Department of Conservation and Land Management, Perth, Western Australia.

McKenzie, N. L., Hopper, S. D., Wardell-Johnson, G. and Gibson, N., 1996. Assessing the conservation reserve system in the Jarrah forest region. Journal of the Royal Society of Western Australia 79: 241-248.

Mills, J., 1989. The impact of man on the northern Jarrah forest from settlement in 1829 to the Forests Act 1918. Pp. 229-279 in The Jarrah forest: a complex Mediterranean ecosystem, edited by B. Dell, J. J. Havel and N. Malajczuk, Kluwer Academic Publishers, Dordrecht, The Netherlands.

Morris, K., Johnson, B., Rooney, J. and Ward, C., 2000. The short-term impacts of timber harvesting and associated activities on the abundance of medium-sized mammals in the Jarrah forest of Western Australia. Pp. 60-70 in Conservation in production environments: managing the matrix, edited by J. L. Craig, N. Mitchell and D. A. Saunders, Surrey Beatty and Sons, Chipping Norton, NSW, Australia.

Morris, K., Johnson, B., Orell, P., Gaikhorst, G., Wayne, A. and Moro, D., 2003. Recovery of the threatened chuditch (Dasyurus geoffroii): a case study. Pp. 435-451 in Predators with pouches: the biology of carnivorous marsupials, edited by M. Jones, C. R. Dickman and M. Archer, CSIRO Publishing, Melbourne.

Nelson, J. L., Morris, B. J., 1994. Nesting requirements of the Yellow-tailed Black-cockatoo, Calyptorhynchus funereus, in Eucalyptus regnans forest, and implications for forest management. Wildlife Research 21: 267-278.

Nichols, O. G. and Muir, B., 1989. Vertebrates of the Jarrah forest. Pp. 133-153 in The Jarrah forest: a complex Mediterranean ecosystem, edited by B. Dell, J. J. Havel and N. Malajczuk, Kluwer Academic Publishers, Dordrecht, The Netherlands.

Noon, B. R. and McKelvey, K. S., 1996. Management of the Spotted Owl - A case history in conservation biology. Annual Review of Ecology and Systematics 27: 135-162.

Norton, T. W. and Kirkpatrick, J., 1995. Sustainable forestry the urgency to make the myth a reality. Pp 240-248 in Conserving Biodiversity. Threats and Solutions, edited by R.A. Bradstock, , T. D. Auld, D.A. Keith, R.T. Kingsford, D. Lunney, and D. P. Silvertsen,. Surrey Beatty and Sons, Chipping Norton, NSW, Australia.

Norwood, C., Wardell-Johnson, G., Majer, J. D., Williams, M., 1995. Short-term influences of edge effect and gap creation on bird populations in Jarrah forest near Dwellingup, Western Australia. Australian Forestry 58: 48-57.

RAC, 1993. Ecological impacts of forest use: a survey of completed research. Research paper no. 9. Resource Assessment Commission, Canberra.

Rhind, S. G., 1998. Ecology of the Common Brushtail phascogale in Jarrah forest of southwestern Australia. PhD thesis, School of Biological Sciences and Biotechnology. Perth, Western Australia, Murdoch University.

Rhind, S. G., 1996. Habitat tree requirements and the effects of removal during logging on the marsupial Common Brushtail phascogale (Phascogale tapoatafa tapoatafa) in Western Australia. The Western Australian Naturalist 21: 1-21. 
Risbey, D.A., Calver, M.C., Short, J., Bradley, J.S. and Wright, I.W., 2000 The impact of cats and Foxes on the small vertebrate fauna of Heirisson Prong, Western Australia: II. A field experiment. Wildlife Research 27: 223-235

Russell, E., Rowley, I., 1998. The effects of fire on a population of Red-winged Fairy-wrens Malurus elegans in Karri forest in southwestern Australia. Pacific Conservation Biology 4: 197-208.

Saunders, D. A., 1982. The breeding behaviour and biology of the short-billed form of the White-tailed Black Cockatoo Calyptorhynchus funereus. Ibis 124: 422-455.

Scarff, F. R., Rhind, S. G. and Bradley, J. S., 1998. Diet and foraging behaviour of brush-tailed phascogales (Phascogale tapoatafa) in the jarrah forest of south-western Australia. Wildlife Research 25: 511-526.

Shearer, B. L. and Tippett, J. T., 1989. Jarrah dieback: The dynamics and management of Phytophthora cinnamomi in the Jarrah (Eucalyptus marginata) forest of south-western Australia. Research Bulletin No. 3, Department of Conservation and Land Management, Perth, Western Australia.

Steiger, J. H. and Fouladi, R. T., 1997. Noncentrality interval estimation and the evaluation of political models. Pp. 221-257 in What if there were no significance tests?, edited by L. L. Harlow, S. Mulaik and J. H. Steiger, Lawrence Erlbaum Associates, Mahwah, New Jersey, USA.

Shortridge, G. C., 1909. An account of the geographical distibution of the marsupials and monotremes of South-west Australia, having special reference to the specimens collected during the Balston Expedition of 1904-1907. Proceedings of the Zoological Society of London 55: 803-847.

Shortridge, G. C., 1936. Field notes (hitherto unpublished) on Western Australian mammals south of the Tropic of Capricorn (exclusive of Marsupialia and Monotremata), and records of specimens collected during the Balston expeditions (November 1904 - June 1907). Proceedings of the Zoological Society of London 1936: $743-749$.

Stoate, T.N., 1947. Report on the operations of the Forests Department for the year ended 30th June 1947. Forests Department of Western Australia.

Stoate, T. N. and Bednall, B. H., Undated. The jarrah and forestry practice. Unpublished manuscript archive no. 011/ 771, Woodvale library, Department of Conservation and Land Management, Western Australia.

Stoneman, G. L., Bradshaw, FJ., Christensen, P., 1989. Silviculture. Pp. 335-355 in The Jarrah forest: a complex Mediterranean ecosystem, edited by B. Dell, J. J. Havel and N. Malajczuk, Kluwer Academic Publishers, Dordrecht, The Netherlands.

Stoneman, G. L., Rayner, M. E. and Bradshaw, F. J., 1997. Size and age parameters of nest trees used by four species of parrot and one species of cockatoo in south-western Australia: Critique. Ети 97: 94-96.

Storr, G. M., 1991. Birds of the south-west division of Western Australia. Records of the Western Australian Museum, Supplement 35.

Strahan, R., (Ed.) 2000. The Mammals of Australia. Reed Books, Chatswood, New South Wales.

Strehlow, K., Bradley, J. S., Davis, J. and Friend, G. R., 2002. Short term impacts of logging on invertebrate communities in Jarrah forests in south-west Western Australia. Forest Ecology and Management 162: 165-184.

Suter, G. W., 1996. Abuse of hypothesis testing statistics in ecological risk assessment. Human and Ecological Risk Assessment 2: $331-347$.
Taylor, B. L., Gerrodette, T., 1993. The uses of statistical power analysis in conservation biology: the vaquita and northern spotted owl. Conservation Biology 7: 489-500.

Thackway, R., Cresswell, I. D., 1995. An interim biogeographic regionalisation for Australia: a framework for setting priorities in the national reserves system cooperative program, Version 4.0. Australian Nature Conservation Agency, Canberra.

Tille, P. and Lantske, N., 1990. The Busselton-Margaret River - Augusta land capability study. Land Resources Series No. 5, Western Australian Department of Agriculture, Perth.

Turner, M.G., Gardner, R.H. and O’Neill, R.V., 1995. Ecological dynamics at broad scales ecosystems and landscapes. BioScience Supplement, Science and biodiversity Policy 29-35.

Turner, M.G., Hargrove, W.W., Gardner, R.H. and Romme, W.H., 1994. Effects of fire on landscape heterogeneity in Yellowstone National Park, Wyoming. Journal of Vegetation Science 5, 731-742.

Twigg, L.E. and King, D.R., 1991 The impact of fluoracetatebearing vegetation on native Australian fauna: a review. Oikos 61: 412-430.

Wallace, W. R., 1965. Fire in the jarrah forest environment. Journal of the Royal Society of Western Australia 49: 33-44.

Ward, D. J., Lamont, B. B. and Burrows, C. L., 2001. Grass trees reveal contrasting fire regimes in eucalypt forests before and after European settlement in southwestern Australia. Journal of Forest Ecology 150: 323-329.

Wardell-Johnson, G., 2000. Responses of forest eucalypts to moderate and high intensity fire in the Tingle Mosaic, southwestern Australia: comparisons between locally endemic and regionally distributed species. Austral Ecology 25: 409-421.

Wardell-Johnson, G. W. and Calver, M. C., 2002. Maintaining Ecosystem Health and Vitality - Viewpoint Two. Assessing health and vitality in the forested ecosystems of south-western Australia. Pp. 24-27 in Forest forum: Science and forest management, edited by C. C. o. W. Australia, Conservation Commission of Western Australia, Perth, Western Australia.

Wardell-Johnson G. and Christensen P., 1992. A review of the effects of disturbance on wildlife of the Karri forest. Pp. 33-58 in Research on the Impact of Forest Management in south-west Western Australia, edited by A. A. Burbidge. Occasional paper 2/92. Department of Conservation and Land Management.

Wardell-Johnson, G. and Horwitz, P., 1996. Conserving biodiversity and the recognition of heterogeneity in ancient landscapes: a case study from south-western Australia. Forest Ecology and Management 85: 219-238.

Wardell-Johnson, G. and Horwitz, P., 2000. The recognition of heterogeneity and restricted endemism in the management of forested ecosystems in south-western Australia. Australian Forestry 63: 218-225.

Wardell-Johnson, G. and Nichols, O., 1991. Forest wildlife and habitat management in southwestern Australia: knowledge, research and direction. Pp. 161-192 in Conservation of Australia's forest fauna, edited by D. Lunney, The Royal Zoological Society of New South Wales, Mosman, New South Wales.

Wardell-Johnson, G. and Roberts, J. D., 1993. Biogeographic barriers in a subdued landscape: the distribution of the Geocrinia rosea (Anura: myobatrachidae) complex in south-western Australia. Journal of Biogeography 20: 95-108.

Wardell-Johnson, G. and Williams, M., 1996. A floristic survey of the Tingle Mosaic, south-western Australia. Journal of the Royal Society of Western Australia 79: 249-276. 
Wardell-Johnson, G., Williams, J., Hill, K. and Cummings, R., 1997. Evolutionary biogeography and contemporary distribution of eucalypts. Pp 92-128 in Eucalypt Ecology: Individuals to Ecosystems, edited by J. Williams, and J. Woinarski, (eds)., Cambridge University Press, United Kingdom.

Watson, P. and Wardell-Johnson, G., in press. Fire frequency and time-since-fire effects on the open-forest and woodland flora of Girraween National Park, south-east Queensland. Austral Ecology.

Wayne, A., Rooney, J., Ward, C., Wheeler, I. and Mellican, A., 2001. Spotlight surveys to investigate the impacts of timber harvesting and associated activities within the jarrah forest of Kingston State Forest, with particular reference to the koomal (Trichosurus vulpecula) and ngwayir (Pseudocheirus occidentalis): Kingston Project progress report. Department of Conservation and Land Management, Perth, Western Australia.

Wayne, A., Ward, C., Rooney, J. and Wheeler, I., 2000. The immediate impacts of timber harvesting and associated activities on the ngwayir (Pseudocheirus occidentalis) in the jarrah forest of Kingston State Forest Block: progress report. Department of Conservation and Land Management, Perth, Western Australia.

Watson, J., Freudenberger, D. and Paull, D., 2001. An assessment of the focal-species approach for conserving birds in variegated landscapes in south-eastern Australia. Conservation Biology 15: 1364-1373.
Whitford, K. R., 2001. Dimensions of tree hollows used by fauna in the jarrah forest: improving the dimensional description of potentially usable hollows. CALMScience 3: 499-511.

Whitford, K. R., 2002. Hollows in jarrah (Eucalyptus marginata) and marri (Corymbia calophylla) trees - I. Hollow sizes, tree attributes and ages. Forest Ecology and Management 160: 201-214.

Whitford, K. R. and Williams, M. R., 2001. Survival of jarrah (Eucalyptus marginata Sm.) and marri (Corymbia calophylla Lindl.) habitat trees retained after logging. Forest Ecology and Management 146: 181-197.

Whitford, K. R. and Williams, M. R., 2002. Hollows in jarrah (Eucalyptus marginata) and marri (Corymbia calophylla) trees - II. Selecting trees to retain for hollow dependent fauna. Forest Ecology and Management 160: 215-232.

Williams, M. R. and Faunt, K., 1997. Factors affecting the abundance of hollows in logs in Jarrah forest of south-western Australia. Forest Ecology and Management 95: 153-160.

Williams, M. R., Abbott, I., Liddelow, G. L., Vellios, C., Wheeler, I. B. and Mellican, A. E., 2001. Recovery of bird populations after clearfelling of tall open eucalypt forest in Western Australia. Journal of Applied Ecology 38: 910-920.

Woodward, B. H. 1909. Extinct marsupials of Western Australia. Geological Magazine, London 6: 210-212.

Young, J. T., 1994. The future - effects of plant disease on society. Joumal of the Royal Society of Western Australia 77: 185-186. 